\title{
Miedos de Guerra y Ecos de Frontera: la posición de España ante una alianza franco-lusa durante la Guerra de Holanda (1672-1679)
}

\author{
Antonio José RodríGuez HeRnández* \\ UNED
}

\author{
Fears of War and Frontier Echoes: the position of Spain \\ in perspective of an alliance between Portugal and France \\ during the Franco-Dutch War (1672-1679)
}

\begin{abstract}
RESUMEN SUMMARY
En este texto se aborda las relaciones entre España y Portugal desde una nueva perspectiva, teniendo en cuenta el factor desestabilizador que supuso la diplomacia francesa y su interés por que ambas se enfrentaran en una nueva guerra. Durante esta época Portugal intentó reubicarse dentro del contexto internacional, teniendo que hacer frente a una gran inestabilidad interna, la pretensión francesa de una alianza más estrecha y la necesidad de reafirmarse como potencia. España, que también compartía problemas internos muy parecidos, siempre vio con preocupación el acercamiento franco-luso, y cualquier eco de movilización en la frontera era visto con miedo ya que podría suponer un nuevo enfrentamiento que lograría desestabilizar aún más el precario equilibrio de la Monarquía Hispánica en Europa.

This text is an approach to the relationships between Spain and Portugal from a new perspective, keeping in mind the destabilizing factor that was the French diplomacy and his interest for that both they faced in a new war. During this time Portugal tried to be relocated inside the international context, having to make in front of an internal uncertainty, the French interest of a narrower alliance and the necessity of being reaffirmed like an international power. Spain shared internal similar problems, and always observed with concern the approach between Portugal and France. Any echo of military mobilization in the frontier was done with fear, since it could suppose a warlike new confrontation that would be able to destabilize even more the precarious balance of the Hispanic Monarchy in Europe.
\end{abstract}

* Abreviaturas utilizadas: Archivo General de Simancas (AGS): Guerra Antigua (GA), Estado (E); Archivo Histórico Nacional (AHN); Biblioteca Nacional (BN); legajo (Leg.); manuscrito (Ms.); folio (f.). Este trabajo ha sido realizado gracias a la ayuda de los proyectos financiados por el Ministerio de Economía y Competitividad: Comercio y Finanzas Internacionales en una España en Transición, 1680-1721 (HAR2011-25907) y Conservación de la Monarquía y Equilibrio Europeo entre los siglos XVII y XVIII (HAR2012-37560-C02-01). 


\section{PALABRAS CLAVE: KEY WORDS:}

España, Portugal, Francia, Ejército, Frontera, Diplomacia y Relaciones Internaciones.
Spain, Portugal, France, Army, Frontier, Diplomacy and International Relationships.

La Paz de Lisboa de 1668 abrió un nuevo marco de entendimiento entre España y Portugal, nunca exento de problemas, y que estuvo desde el primer momento surcado de innumerables desafecciones y afrentas mutuas. Cualquier cuestión, por nimia que pareciera, podía desestabilizar la frágil balanza y desencadenar acontecimientos ciertamente negativos de cara a la conservación de la paz.

La política bilateral de ambas naciones estuvo constantemente caracterizada por el recelo, y las relaciones de los embajadores, sus cartas o los asuntos tratados en Madrid por el Consejo de Estado nos dan buena muestra de ello. Durante esta época ambos gobiernos se tuvieron que enfrentar a problemas de credibilidad y tensiones políticas internas, lo que hizo que éste fuera un terreno abonado para estas actitudes de distensión. Durante la década de 1670 una debilitada España, con un rey niño y poco capacitado, se medía a una nueva nación portuguesa con una casa real demasiado novel y muy preocupada por el reconocimiento internacional, que tenía que demostrar su realeza y temía ser tildada de rebelde o con pocos derechos al trono. En ambos casos la sangre real se demostró un elemento distorsionador y de tensión, ya fuera por un bastardo real, Juan José de Austria; o por una casa de Braganza con importantes tensiones familiares, como la conjura que había llevado al poder a Pedro frente a su hermano Alfonso. Los complots internos, y la posible participación —o apoyo— del país vecino, fueron siempre elementos de tensión o suspicacia.

Junto con el factor interno, también hubo un elemento externo que influyó mucho en la relaciones y que hasta el momento no se ha tenido demasiado en cuenta. Francia siempre estuvo interesada en estrechar sus lazos con Portugal al mismo tiempo que intentaba desacreditar a España; por lo que su política exterior, su diplomacia y sus guerras fueron un elemento desestabilizador. La firma del tratado secreto franco-luso de 1667 marcó un importante hito, y contribuyó a trazar el devenir hispano-portugués de la década siguiente. Durante este tiempo las relaciones entre España y Portugal no pueden ser vistas simplemente como unas relaciones bilaterales al uso, ya que en ellas hubo demasiadas influencias, entre ellas el influjo externo de Francia y sus ansias de dominio europeo. El tratado secreto asoció momentáneamente a ambas naciones en sus intereses contra España, pero pronto Portugal incumplió una de sus cláusulas más importantes al firmar una paz por separado con España. Pese a ello Francia siempre estuvo muy interesada en renovar su alianza con Portugal, a la vez que sembraba vientos de desconfianza hacia España. 


\section{ALIANZAS INCIERTAS: LOS INTENTOS DE ESPAÑA Y FRANCIA DE ALIARSE CON PORTUGAL}

Tras la consecución de la Paz, la breve embajada del Barón de Bateville en Lisboa se caracterizó desde el primer momento por ser incapaz de arreglar muchos de los asuntos pendientes, como el tema de las restituciones ${ }^{1}$. Quizá el envío del Barón de Bateville como embajador no fuera adecuado, ante los inconvenientes alegados ${ }^{2}$, y la dilatación de su salida de Madrid, pese a las órdenes del Consejo de Estado ${ }^{3}$, influyendo en todo ello la pérdida de confianza que implicó su polémica embajada en Londres y el incidente que mantuvo con el embajador francés. El borgoñón fue recibido oficialmente por el príncipe Pedro con gran agasajo tres meses después de su llegada, en febrero de $1669^{4}$. Su limitado periodo en Portugal, ante su prematura muerte en Lisboa en 1670, no ayudó a mejorar la situación, al igual que el tiempo perdido hasta su llegada.

La elección del Conde de Humanes como embajador significó un cambio de dirección, ya que como diplomático se demostraría mucho más capaz que su predecesor. Con inteligencia supo conocer las innumerables grietas del nuevo régimen portugués, y su lucha de facciones, al mismo tiempo que había infiltrado espías en el gobierno que lo mantuvieron muy bien informado de los entresijos políticos ${ }^{5}$. Todo ello le convertiría en el antagonista de su homólogo portugués en Madrid -el Marqués de Gouveia-, que se tornaría en su enemigo, el cual repetidamente intentó desacreditarle ante la corte madrileña y el pueblo de Lisboa, ante sus celos ${ }^{6}$.

A pesar del incumplimiento luso del tratado secreto firmado con Francia en $1667^{7}$, los recelos franceses serían pasajeros. Portugal seguía siendo un importante peón en el juego de astucia que Luis XIV mantuvo frente a España. La situación estratégica, y la alianza entre ambas naciones beneficiaba los intereses galos, ya que cualquier presunción de ataque o inestabilidad en la frontera podría retraer fuerzas militares y medios a la cada vez más debilitada España, y potenciar así las victorias francesas en Flandes, Italia o la frontera catalana en la guerra que se avecinaba.

En la primavera de 1672 el embajador español se hizo con las instrucciones secretas del nuevo representante francés en Lisboa ${ }^{8}$, algo que años después tam-

Tema abordado extensamente en VALLADARES, 1998, 266 y ss.

2 Consulta del Consejo de Estado, 22 de agosto 1668. AGS, E, Leg. 2.614.

3 Consultas del Consejo de Estado, 21 de junio, 5, 20 y 26 de julio 1668. AGS, E, Leg. 2.614.

4 DU MONT, 1739, 382. Carta del Barón de Bateville, Lisboa, 21 de febrero 1669. AGS, E, Leg. 2.615.

5 VALLADARES, 1998, 272/273.

6 Cartas del Conde de Humanes, Lisboa, 6 de febrero y 20 de marzo 1673. AGS, E, Leg. 2.624.

7 ABREU Y BERTODANO, 1751, 118 y 128.

8 Carta a su Majestad, Lisboa, 9 de mayo 1672. Instrucción (traducida del francés) que el Sr. de D'Aubeville debe guardar en su jornada que hace al reino de Portugal, Saint-Germain en Laye, 19 de noviembre 1671. AGS, E, Leg. 7.049. Me he basado en la versión española, ya que lo que me interesa es la recepción de la noticia en España. Sobre el original: DE CAIX DE SAINT-AYMOUR, 1886, 123 y ss. 
bién se volvería a conseguir. En estas instrucciones de 34 puntos Francia mostraba sus bazas y el papel asignado a Portugal dentro del complicado juego de cartas que venía desarrollando en Europa. La misión principal del enviado francés era persuadir a los portugueses para que tomaran partido por Francia - tal y como habían hecho la mayor parte de los príncipes de Europa, como decía la instrucción-, uniéndose ambas naciones en una liga ofensiva y defensiva a la que se podría sumar Inglaterra. La lucha que se avecinaba era contra Holanda, por lo que Francia pretendía el apoyo incondicional de Portugal, lo que de paso contribuiría a su ruptura con España, al ser las Provincias Unidas y España dos aliados «inseparables» tal y como decía el noveno punto. Las instrucciones reconocían que la quiebra de la paz sería traumática, ante el escaso margen desde la reciente paz, por lo que había que tentar a Portugal con la opción de recuperar los territorios coloniales perdidos frente a los holandeses. Para facilitar su restitución, los franceses ofrecían una escuadra de 6 navíos para actuar en las Indias Orientales, algo que llegando el caso se podría negociar al alza hasta los 12 buques, siempre y cuando los portugueses accedieran a los demás términos de la liga. De facto lo importante no era la lucha por recuperar el imperio colonial portugués o dificultar a los holandeses el acceso a oriente, sino que Portugal se enfrentara a España, por lo que de nada servía si Portugal declaraba la guerra a Holanda y no se embarazaba en una nueva lucha contra España, acción con la que cumpliría el ya olvidado tratado secreto de 1667. La corte francesa era consciente de que la guerra generaba el rechazo del pueblo portugués, y muy especialmente a sus clases más bajas, por lo que sería difícil convencerlo. Así la actuación del enviado galo se debía centrar en persuadir a los cabos de guerra del ejército portugués, abriendo el dinero el camino del convencimiento. Para ello el propio Colbert debía abrir las arcas francesas y suministrar una cantidad indefinida para pensiones y sobornos a los mandos del ejército y ministros que optaran por respaldar la postura gala Todas las negociaciones con el príncipe Pedro debían realizarse con disimulo, debiendo implicar a cuantos menos ministros mejor, ante el conocimiento de que habría oposición dentro del Consejo de Estado. Los designios franceses no tenían que ser conocidos, por lo que se debía obrar con cuidado, ya que se reconocía que España mantenía a demasiados informadores. Incluso una de las clausulas especificaba que los intereses de Francia solo debían ser revelados al comisario que decidiese el príncipe para tratar el asunto, y no al resto de los ministros. Si se encontraba algún rechazo a las propuestas por parte de los ministros portugueses, el enviado francés debía intentar buscar a los más aficionados a Francia, entre los que se encontraba el Marqués de las Minas.

Si Portugal se resolvía a declarar la guerra el apoyo francés sería muy parecido al ya mostrado con anterioridad. Francia se encargaría de enviar y pagar en territorio portugués al mismo número de tropas $^{9}$, pudiendo negociar el enviado

9 Las instrucciones no hacían referencia a la cifra, aunque en el año 1664 -momento en el que el contingente francés fue más importante-, en Portugal se mantuvieron 2 regimientos de infantería y 4 de 
galo su aumento en uno o dos regimientos, siempre y cuando eso favoreciese a que Portugal se librase de sus dudas. En el plano naval Francia se comprometía a ayudar en caso de que Holanda y España atacasen de manera conjunta, aportando 6 fragatas grandes para patrullar las costas portuguesas durante el verano y evitar el corso, y otros 3 navíos pequeños en el estuario del Tajo, estableciéndose el compromiso de que si una flota hispano-holandesa bloqueaba la barra de Lisboa la armada francesa acudiría para evitar el bloqueo. Luis XIV aportaría dinero siempre y cuando los portugueses hicieran instancias de necesitarlo, contribuyendo con 200.000 escudos al año. Cifra a la que se podrían sumar otros 200.000 los tres primeros años de guerra en caso de que los ministros portugueses declararan que no podrían obtener ninguna contribución del pueblo.

Al tratar el posible reparto de las ganancias territoriales en las Indias Orientales y el mundo colonial, si Portugal recuperaba Ceilán, Cochín y Cannanore, los franceses pretendían quedarse a cambio la ciudad de Diu y los derechos de Portugal sobre las islas Molucas. En África, si se arrebataba São Jorge da Mina a los holandeses en el Golfo de Guinea, Francia procuraría obtener a cambio la isla de Santo Tomé; mientras que en América aspiraba a recuperar la ciudad de San Luis, en Brasil, que tiempo atrás había colonizado brevemente. Además, si la guerra contra España progresaba bien, Francia reclamaba la primera plaza marítima con un puerto capaz para navíos de más de 200 toneladas.

Si la astucia, el dinero o la búsqueda de un ministro pro francés fallaba, el enviado de Luis XIV podía incluso llevar sus negociaciones a un estadio superior y declarar la guerra a Portugal, ya que la misión encomendada era primordial, por lo que todo valía, incluso ese miedo superior. La diversión de una guerra entre España y Portugal era el único fin de las pretensiones francesas, posición que contrastaba con la inicial, que aseveraba que los portugueses debían ser convencidos de que «Francia no ha de permitir que España sea señora de Portugal» ${ }^{10}$.

A comienzos de 1673 la Corte portuguesa se debatía con escaso interés entre las opciones geopolíticas y estrategias que se planteaban. Por un lado la idea de una liga que ofrecían los españoles ${ }^{11}$, como la ya esbozada en $1668^{12}$, formulada más para alejar a Portugal de las tesituras francesas que por puro convencimiento. Por otro lado estaba la opción francesa de una actuación conjunta frente a Holan-

\footnotetext{
caballería, unos 3.300 efectivos: Nota de los regimientos antiguos y nuevos de infantería y caballería francesa e inglesa que sirven en el ejército de Portugal, 6 de junio de 1664. AGS, GA, Leg. 2.054. Las fuentes portuguesas avalan el número de regimientos, aunque no son capaces de estimar el tamaño real del contingente: PENIM DE FREITAS, 2007, 89/94.

10 Instrucción (traducida del francés) que el Sr. de D'Aubeville debe guardar en su jornada que hace al reino de Portugal, Saint-Germain en Laye, 19 de noviembre de 1671. AGS, E, Leg. 7.049.

11 Consultas del Consejo de Estado, 4 de enero y 5 de febrero de 1673. Carta del Conde de Humanes, Lisboa, 19 de diciembre de 1672. Carta de su Majestad al Conde de Humanes, Madrid, 26 de enero de 1673. AGS, E, Leg. 2.624.

12 Borrador de Carta de Mariana de Austria al Marqués del Carpio, Madrid, 24 de febrero de 1668. AGS, E, Leg. 2.614.
} 
da, que si bien podía ofrecer compensaciones territoriales supondría a la larga el quebrantamiento de la paz. En esos momentos todo valía para captar a Portugal como aliado, por lo que la lucha diplomática en Lisboa no tuvo cuartel, sucediéndose las quejas mutuas mientras que los portugueses daban largas a ambos bandos. Un claro motivo de resentimiento francés fue la colaboración de las tropas hispanas con el Príncipe de Orange que habían puesto sitio a Charleroy, más allá de las fronteras de las Provincias Unidas ${ }^{13}$. Incluso la pugna franco-española también se libraba en el ámbito del espionaje, ya que el siempre bien informado Conde de Humanes perdió a su confidente principal en la corte lusa, que pudo haber sido comprado por los franceses ${ }^{14}$.

En el caso de la petición española de alianza, el Consejo de Estado portugués fue dilatando su resolución, alargando la materia arguyendo la falta del poder necesario para llevarse a cabo las negociaciones. Pero por encima de todo el Conde de Humanes también reconocía el poco ánimo del príncipe Pedro por concluir su alianza con Francia e Inglaterra en su lucha contra Holanda, ya que difícilmente podía aceptar las condiciones pretendidas sin arriesgar la paz, claro fin de los portugueses ${ }^{15}$. La confirmación de dicha argumentación llegó en marzo de la mano de las inteligencias del Conde de Humanes con los enviados lusos en Inglaterra, los cuales reconocían la dificultad de la liga tripartita que se pensaba establecer a iniciativa francesa ${ }^{16}$. A pesar de ello los franceses intensificaron sus esfuerzos, e incluso intentaron enviar a Schomberg a Portugal con nuevas órdenes para así desencadenar mejores acontecimientos ${ }^{17}$. De nuevo en 1674 la diplomacia española en Lisboa se hacía eco - a través de sus informadores-, de que el proyecto de alianza con Francia no progresaba, algo que ratificaba el propio embajador luso en Londres, a lo que se sumaba el distanciamiento entre Francia e Inglaterra que hacía imposible un acuerdo tripartito ${ }^{18}$.

\section{CONJURAS, ASALTOS Y RECELOS}

En los prolegómenos de la declaración formal de guerra de España a Francia en 1673 el Consejo de Estado seguía debatiendo la conveniencia de tal acción, y aunque la decisión fue claramente positiva, uno de los escollos que muchos con-

13 Carta del Conde de Humanes, Lisboa, 19 de enero de 1673. AGS, E, Leg. 2.624.

14 Consulta del Consejo de Estado, 22 de febrero de 1673. AGS, E, Leg. 2.624.

15 Consulta del Consejo de Estado, 12 de febrero de 1673. Traducción del poder dado por el príncipe de Portugal a su secretario de estado para tratar la liga, traducido del portugués. Cartas del Conde de Humanes, Lisboa, 19, 23 y 30 de enero de 1673. AGS, E, Leg. 2.624.

16 Consulta del Consejo de Estado, 28 de marzo de 1673. Cartas del Conde de Humanes, Lisboa, 14 y 20 de marzo de 1673. Copia de la carta de don Francisco de Melo, embajador de Portugal en Inglaterra escrita al príncipe don Pedro en 10 de octubre de 1672. Copia de la carta que el príncipe de Portugal escribió a don Francisco de Melo, Lisboa, 6 de marzo de 1673. AGS, E, Leg. 2.624.

17 Carta de Mariana de Austria al Conde de Molina, Madrid, 13 de abril de 1673. AGS, E, Leg. 2.624.

18 Carta del Abad de Masserati, Lisboa, 5 de febrero de 1674. AGS, E, Leg. 2.626. 
sejeros exponían era el peligro que suponía la dilatada frontera entre España y Portugal ${ }^{19}$, cada vez más carente de medios, ante el posible apoyo luso a la política agresiva del Rey Sol. De hecho en mayo de 1672 el embajador español en Lisboa se hacía eco de las negociaciones entre portugueses y franceses para formar una alianza contra la débil regencia española. Humanes también certificaba que los portugueses intentaban entretener la salida de más de 60 navíos mercantes holandeses que estaban en Setúbal, dándose orden para que éstos fueran avisados por los agentes hispanos de las intenciones francesas para que tomaran rumbo a Holanda rodeando Irlanda, evitando así que se pudieran encontrar con la Armada francesa aprestada para su captura ${ }^{20}$.

En esa delicada coyuntura nadie podía intuir que su popularidad y las dotes mostradas por el Conde de Humanes se volverían contra él, echando por tierra los avances mostrados en un momento en que las hostilidades parecían ya superadas. Las turbaciones internas, amplificadas ante el polémico perdón general a los conversos, conllevaron la aparición de un movimiento de oposición alfonsista. En septiembre de 1673 se descubría la conjura que pretendía asesinar al regente Pedro, confesando algunos detenidos que Humanes podía estar involucrado. $\mathrm{Si}$ bien éste pudo ejercer ciertos sondeos entre el alfonsismo ${ }^{21}$, no parece que estuviera realmente implicado. En julio de ese año el Consejo de Estado señalaba ante la posibilidad de la mudanza de gobierno que el embajador no tenía órdenes al respecto, ya que no se había barajado tal contingencia ${ }^{22}$. A nivel ejecutivo, tampoco parece que los conjurados tuvieran el apoyo de España y de su ejército para hacerse con el poder, a pesar de las informaciones conseguidas por la Junta de Inconfidentes. En Badajoz — pese a la insinuación de que allí esperaría a Don Alfonso una fuerza de 2.000 infantes y 2.000 caballos para retomar el trono ${ }^{23}$-, no había tantos hombres y en ningún momento se cursaron órdenes al respecto por parte del Consejo de Guerra. De hecho, en aquel momento el ejército de Extremadura llegaba a duras penas a 1.000 efectivos, ya que durante los años anteriores la mayor parte de los contingentes profesionales se fueron reubicando en Catalu$\tilde{n} a^{24}$. La muestra que tuvo lugar en mayo de 1673 indicaba que en la frontera había 483 oficiales y soldados profesionales en un Tercio, 255 milicianos de la provincia y 276 jinetes en cuatro compañías, tropas que ni siquiera eran suficientes para asegurar la defensa de las plazas fuertes ${ }^{25}$.

19 Consulta del Consejo de Estado, 18 de abril de 1673. AGS, E, Leg. 2.391.

20 Consulta del Consejo de Estado, 15 de mayo de 1672. Copia de carta de Manuel de Lira a la reina contando como avisó de las noticias del conde de Humanes en Portugal a los Estados Generales de Holanda, La Haya, 19 de abril de 1672. AGS, E, Leg. 2.694.

21 VALLADARES, 1998, 272/279.

22 Consulta del Consejo de Estado, 16 de julio de 1673. AGS, E, Leg. 2.695.

23 VALLADARES, 1998, 279/280.

24 Junta de Milicias, 8 de octubre y 11 noviembre de 1672. AGS, GA, Leg. 2.270.

25 Diferentes muestras pasadas a la infantería, milicias, caballería y artillería y fechadas el 26 de mayo de 1673. AGS, GA, Leg. 2.300. 
Poco después la situación se agravó todavía más cuando la legación diplomática lusa en Madrid fue asaltada por una muchedumbre airada. El problema de fondo no tenía nada que ver con la conjura lisboeta o con la actitud española frente a los portugueses, ya que se trataba de algo más mundano: la venganza. Desde su llegada a Madrid, el Marqués de Gouveia no había hecho demasiados amigos, ante sus limitadas dotes ${ }^{26}$. Su actitud anti española y el hecho de que había permitido que sus criados y familiares cometieran delitos por las calles y se mezclaran con delincuentes comunes, gozando del amparo diplomático, le había granjeado el odio de las clases populares madrileñas. Cuestión que ocasionó no pocos quebraderos de cabeza y cartas cruzadas entre los consejos de Estado y Castilla, y la Sala de los Alcaldes, «por el escándalo que provocan por ir con cuadrillas de gente armada por la corte maltratando a quien les parece ${ }^{27}$. Tras una pendencia callejera en la calle Hortaleza el día 24 de septiembre, en la que salieron heridos el caballerizo del embajador y uno de sus zapateros, un alcalde de Corte intentó interrogarlos, a lo cual respondieron con la amenaza de vengarse de quien los había herido. Las actividades delictivas de las cuadrillas portuguesas no cesaron, al igual que su hostilidad hacia los alguaciles locales, y en pocos días cortaron dos dedos a un labrador de Arganda que se negó a darles un melón e hiriendo incluso a un Archero de Corps, encendiendo al pueblo madrileño que veía como sus delitos quedaban impunes. La noche del 27 al 28 de septiembre una multitud se concentró en la casa del embajador y la apedreó, consiguiendo provocar a los portugueses, que al ser increpados respondieron con arcabuzazos, hiriendo a varias personas. El gentío respondió con el incendio de la caballeriza, que también saqueó. La justicia actuó muy tarde —quizá interesadamente- y no pudo evitar la lucha, lo que le costó el destierro al Alcalde de Corte y que la monarquía debiera explicar tan peliagudo asunto al resto de embajadores presentes en Madrid ${ }^{28}$.

Lo ocurrido enturbiaba todavía más las relaciones bilaterales, llegando a plantearse incluso el intercambio de embajadores. Incertidumbres acrecentadas ante los informes que venían de la frontera, en donde crecía la desconfianza y las prevenciones de guerra. Como se informaba desde Extremadura, «cada día doblan su desconfianza aquellos fronterizos y dan a entender a los pueblos que quere-

26 Tras varios años en Madrid, Pötting, el Embajador imperial en Madrid, no podía decir de él más que: «buen cavallero, pero no muy platico en lo ceremonial de los Embaxadores». Nota del 9 de abril de 1672. NIETO NUÑO, 1990, Tomo II, 258.

27 Consulta del Consejo de Estado, 11 de septiembre de 1672. Carta del secretario Diego de la Torre al Duque de Alburquerque, 11 de septiembre de 1672. AGS, E, Leg. 2.694.

${ }_{28}$ Consultas del Consejo de Estado, 29 de septiembre, 1 y 19 de octubre 1673. Copia del papel del Conde de Humanes para el secretario Francisco Correa de la Cerda, Lisboa, 3 de octubre de 1673. Traducción del papel del Marqués de Gouveia para su majestad, s/f. Carta del secretario don Diego de la Torre al Nuncio y embajadores de Alemania y Francia, octubre 1673. AGS, E, Leg. 4.048. Carta de la Reina Gobernadora al Conde de Humanes, Madrid, 28 de septiembre de 1673. Relación de los excesos cometidos por la familia del embajador de Portugal hasta lo ocurrido el día 27 de septiembre de 1673. AGS, E, Leg. 7.049. La versión portuguesa de dicho asunto en: VALLADARES, 1998, 280. 
mos moverles guerra con intento de reducirlos al que tiene aquel gobierno» ${ }^{29}$. La noticia era realmente preocupante, ya que los portugueses mantenían que España deseaba la guerra y que pretendía invadirles ${ }^{30}$, algo que estaba muy lejos de la realidad. En esos momentos Madrid se enfrentaba nuevamente a Francia y no podía permitirse el envío de dinero u hombres a la Raya. A la escalada de miedos tampoco ayudó la decisión portuguesa de no enviar un nuevo embajador a Madrid hasta más de un año después ${ }^{31}$.

En los espacios cortesanos madrileños siempre permaneció en el ambiente la idea de que Francia enturbiaba continuamente las relaciones con el vecino luso. A comienzos de octubre de 1673 en Madrid se pensaba que Francia era la que más había ganado con lo ocurrido, dándose una buena excusa a los portugueses ${ }^{32}$. El Duque de Alburquerque temía la ruptura entre ambos países, la cual sin duda estaría apoyada y sufragada por Francia. Incluso llegaba a afirmar que en cuestión de 8 días la Armada francesa podía conducir a un destacamento de 5.000 o 6.000 infantes a Lisboa para poder así atacar España. Tal posibilidad alarmaba a los más escépticos, y más cuando se reconocía que la frontera extremeña estaba custodiada por apenas 400 infantes y 80 jinetes, reconociéndose que no se debía «dudar que ellos [los portugueses] por pocas fuerzas que tengan serán más que las nuestras para hacernos ofensa». Tampoco se dudaba que tal opción bélica convenía a los intereses galos, pues el mejor camino para lograrlos en el norte de Europa era crear una diversión estratégica en la frontera portuguesa, ya que de ese modo España sería incapaz de socorrer Flandes, o asistir con medios al Emperador, con lo que Francia podría conseguir así su objetivo de hegemonía europea $^{33}$. Dentro de este ambiente hostil y de tensión, algunos opinaban que la posibilidad de una guerra entre España y Portugal era obvia, pudiendo ésta estar motivada a factores como la pasión, algún fin premeditado de antemano, o de manera especial a lo que se calificaba como la rendición lusa «a los ympulsos y siniestros ynfluxos de Francia» ${ }^{34}$.

Los españoles temían seriamente la colaboración militar portuguesa. En el plano naval la posibilidad de que la armada francesa utilizase puertos lusos como bases seguras era un peligro inminente ante el sensible impacto que tendría en el

29 Consulta del Consejo de Estado, 10 de octubre 1673. Carta de don Luis Ferrer, Badajoz, 13 de octubre de 1673. AGS, E, Leg. 4.048.

30 Consulta del Consejo de Estado, 6 de octubre 1673. AGS, E, Leg. 4.048

31 Consultas del Consejo de Estado, 11 de julio de 1674 y 25 de enero de 1675. AGS, E, Leg. 2.627 y 2.629 f. 7.

32 El Duque de Alburquerque opinaba con miedo que los franceses «infundirán la noticia de que los castellanos tomaran armas contra ellos [los portugueses]y que incitarán el odio contras los castellanos». Carta del Duque de Alburquerque, Madrid, 6 de octubre 1673. AGS, E, Leg. 4.048.

33 Consulta del Consejo de Estado, 6 de octubre 1673. AGS, E, Leg. 4.048. Voto del Marqués de Castel-Rodrigo, Madrid, 18 de diciembre 1674. Consulta del Consejo de Estado, 30 de diciembre de 1674. AHN, E, Leg. 2.799.

34 Carta del Duque de Alburquerque en el Consejo de Estado, Madrid, 6 de octubre 1673. AGS, E, Leg. 4.048. 
comercio y la llegada de los galeones de la plata. La llegada a finales de 1672 de una escuadra francesa de 12 navíos a Lisboa encendió todas las alarmas, pese a que ambas naciones estaban formalmente en paz, ya que se esperaba que dicha escuadra pudiera tomar represalias en algún puerto español debido a las presas realizadas por los corsarios holandeses que se recogían en las costas cantábricas, o intentase sorprender a la próxima flota de Indias, hechos que nunca sucedieron para el alivio de los consejos de Estado e Indias ${ }^{35}$. Ya en plena guerra entre España y Francia, al peligro de la colaboración militar se le sumó el del contrabando. Navíos mercantes franceses recalaban en el puerto de Faro, y allí transvasaban sus mercancías -especialmente lencería y otros productos textiles- a barcos de menor calado que con total impunidad comerciaban en Cádiz, Sanlúcar y Huelva. Un tema bilateral que durante meses fue complicado de solucionar, y que nunca se llegó a arreglar satisfactoriamente ${ }^{36}$.

\section{EL COMIENZO DE LA GUERRA DE HOLANDA Y EL CAMBIO EN EL PANORAMA INTERNACIONAL}

España comunicó su declaración formal de guerra a Francia al príncipe Pedro a comienzos de febrero de $1674^{37}$, muchos meses después de que se confirmara el Tratado de La Haya con Holanda (30 de agosto 1673) y de que España declarase la guerra (abril 1673) ${ }^{38}$, a pesar de que ya un año antes el ejército de Flandes venía colaborando con los neerlandeses en su defensa frente a los intentos expansionistas franceses ${ }^{39}$. La simbólica demora venía motivada fundamentalmente por las tensiones acaecidas en los últimos meses de la presencia del Conde de Humanes en Lisboa, la conjura lisboeta, y la llegada del Abad de Masserati como nuevo embajador ${ }^{40}$. Tan importante retraso también demuestra la tensión del momento, y que en Lisboa incluso circulase el rumor de que España se preparaba para invadir Portugal, alegando para ello que a la firma de la paz de 1668 Carlos II era menor de edad y hasta el momento se había visto obligado a su aceptación. El Marqués de Gouveia parecía ser uno de los instigadores de esta opinión, y el origen de una parte de los rumores que indicaban que en toda Castilla se reclutaban importantes contingentes de tropas y se reforzaban las guarniciones fronterizas ${ }^{41}$ Todo esto no era cierto, ya que si bien se reclutaban tropas para la guerra contra

35 Cartas del Conde de Humanes, Lisboa, 24 de diciembre de 1672 y 9 de enero de 1673. Consultas del Consejo de Estado, 5, 9 y 22 de enero y 26 de febrero de 1673. AGS, E, Leg. 2.624.

36 Carta del Abad de Masserati, Lisboa, 25 de diciembre 1673. Consulta del Consejo de Estado, 9 de enero 1674. AGS, E, Leg. 2.626.

37 Carta del Abad de Masserati, Lisboa, 5 de febrero y 7 de mayo 1674. AGS, E, Leg. 2.626.

38 HERRERO SÁNCHEZ, 2000. GIL PUYOL, 1996, 92. SERRANO DE HARO (Madrid, 1992): 574/5.

39 ALMIRANTE, 1923, pp. 290/299. Carta del Conde de Monterrey, Gobernador de los Países Bajos, 29 de junio 1672. AGS, E, Leg. 2.118. Carta del Conde de Molina, 19 de junio 1672. AGS, E, Leg. 2.120.

40 Sobre la correspondencia de este embajador: CARDIM, (Lisboa, 2005): 95/128.

41 Carta del Abad de Masserati, Lisboa, 6 de noviembre de 1673. AGS, E, Leg. 2.626. 
Francia, las guarniciones de la frontera portuguesa no habían recibido ni un solo reemplazo, y cada día disminuían.

El rumor de un posible enfrentamiento con España continuó particularmente en el ambiente durante los meses siguientes, algo que no es fácil de interpretar. Más allá de la Corte, en ciudades como Zamora, en noviembre de 1673 se conocían las posibles intenciones portuguesas de declarar la guerra, como se hacía eco un diario contemporáneo ${ }^{42}$. Por parte hispana no parece que hubiera provocación alguna, especialmente en el ámbito militar, en donde era evidente que las preocupaciones españolas no estaban precisamente en la frontera hispano-lusa. De hecho parece que la idea, más allá de la más que dudosa implicación del Conde de Humanes en la conspiración del verano de 1673, no dejaba de ser un aglutinante para evocar el miedo colectivo hacía una nueva guerra, y que el príncipe Pedro estaba sacando un buen partido de él. Tras la convocatoria de Cortes, a comienzos de 1674, la diplomacia española sospechaba que Pedro se coronase como rey -algo que finalmente no ocurrió-, al mismo tiempo que temía que las fuerzas armadas del país se reforzasen, y que la monarquía lusa consiguiera más medios económicos para el mantenimiento de su entramado militar, siendo éste a la postre el verdadero éxito de todos estos bulos y miedos antiespañoles ${ }^{43}$. Una escalada de preparativos bélicos que según los informes españoles estaba motivada más al temor de Pedro a cualquier oposición interna que al miedo a una agresión externa, por lo que a fin de cuentas la paz no parecía en entredicho. De hecho la opción de una nueva guerra contra España no parecía tener excesivos partidarios entre el pueblo llano, ya que en las Cortes muchos municipios se mostraron firmes en su posición antibélica por lo que una nueva guerra representaría para sus habitantes, haciendas y bienes ${ }^{44}$.

A finales de 1673 llegaba a La Haya un agente portugués que residía en Ámsterdam con una carta que acaba de llegar de la Corte lusa. En ella se aseguraba a la República holandesa que en caso de que «el Príncipe [Pedro II] entrase en mala inteligencia con España, conservarían los Estados [Generales] la buena que tienen con Portugal...» ${ }^{45}$. Dicha noticia suponía nuevamente un eco de alarma para la diplomacia española, que rápidamente despachó la noticia a Madrid. Ciertamente este tipo de avisos - fueran ciertos, aproximados o totalmente desacertados o fuera de contexto- alarmaban a una Corte madrileña demasiado ocupada ante los envites militares franceses y las tensiones internas de gobierno. Lo cierto es que nunca se rompieron las hostilidades, pese a las presiones francesas, aunque el temor siempre permaneció en el ambiente, aumentando al declararse la

42 LORENZO PINAR y VASALLO TORANZO, 2001, 44 (edición basada en el manuscrito original de la época).

43 Carta del Abad de Masserati, Lisboa, 5 de febrero 1674 (bis). Consulta del Consejo de Estado, 21 de febrero 1674. Relación del dinero que es necesario para el sustento de la guarnición de las fronteras del reino y entretenidos y gastos que se hacen en esta Corte (de Portugal)..., s/f. AGS, E, Leg. 2.626.

44 Consulta del Consejo de Estado, 23 de mayo 1674. AGS, E, Leg. 2.626.

45 Consulta del Consejo de Estado, 30 de enero 1674. AGS, E, Leg. 2.550. 
guerra abierta entre España y Francia. La nueva situación bélica también alarmaba en las fronteras españolas con Portugal, más si cabe cuando por esas fechas los portugueses hacían grandes prevenciones a lo largo de la Raya. Cuando a finales de 1673 el Conde de Aranda tomaba posesión de su puesto como Capitán General de Galicia despachó distintas misivas a los Consejos de Estado y Guerra aludiendo a la mala situación militar del reino, escasamente defendido, y en el que se temía cualquier ataque francés o portugués, al estar la provincia rodeada de enemigos «por mar y por tierra». El recelo a los portugueses en la frontera era claro, y la respuesta del Consejo de Estado en este sentido fue igualmente nítida, determinándose que las «prevençiones se deven limitar a lo preciso, excusando todo motivo de desconfiança» ${ }^{46}$. Pese a ello hubo algunos preparativos en las fronteras, dándose orden para que la Armada estuviese prevenida ante los posibles sucesos que pudieran acaecer ${ }^{47}$.

\section{MIEDOS E INCERTIDUMBRES}

A la altura 1675 la situación estratégica para Francia no era tan clara como cabría esperar, al haberse difuminado ya el efecto de las rápidas victorias logradas ante los holandeses y príncipes alemanes. A lo largo del año anterior los franceses se habían replegado del territorio holandés para atacar los Países Bajos españoles, en donde la situación todavía no se les había mostrado tan favorable ${ }^{48}$ Si bien con poca resistencia habían ocupado el indefenso Franco Condado ${ }^{49}$, la batalla de Seneffe quedó en tablas ante la brillante actuación de la caballería hispánica comandada por el portugués Marqués de Asentar que en el momento más álgido de la batalla estrelló sus fuerzas contra los franceses para dar tiempo a que los imperiales pudieran reorganizarse, lo que le costaría la vida ${ }^{50}$. Las campañas de Turenne para defender la Alsacia francesa y atacar las posiciones aliadas en el Rin fueron un éxito ${ }^{51}$, al igual que la colaboración francesa con los rebeldes de Mesina, que permitiría abrir un nuevo frente bélico en la isla ${ }^{52}$. Pero ni en los Países Bajos, ni en Cataluña -en donde los franceses perdieron varias plazas como Bellaguarde, y fueron derrotados en Maurellas por los españoles ${ }^{53}$-, las cosas iban tan bien. Dentro de este cúmulo de circunstancias era lógico que la diplomacia francesa intentase abrir un nuevo frente en la península con el que desviar parte de los refuerzos hispanos, ya que en esos momentos el enemigo más difícil

46 Consulta del Consejo de Estado, 6 de diciembre de 1673. AGS, E, Leg. 2.696.

47 Consulta del Consejo de Estado, 8 de octubre de 1673. AGS, E, Leg. 2.697.

48 Para una perspectiva general sobre el conflicto: LYNN, 1999, 109/159.

49 QUINCY, 1736 1, 372/394.

50 Carta del Conde de Monterrey, Gobernador de los Países Bajos, Bruselas, 12 de julio de 1674. Consulta del Consejo de Estado, 7 de septiembre de 1674. AGS, E, Leg. 2.126.

51 BÉRENGER, 1987, 392/406.

52 RIBOT, 2002.

53 Órdenes Reales, Madrid, 8 de marzo de 1675. AGS, GA, Leg. 2.339. 
era España, que pese a sus debilidades actuaba de escudo para que el resto de los aliados empezaran a recuperarse. Españoles, portugueses y franceses se mostraban de acuerdo en la idea contrastada por la historia reciente de que la Monarquía Hispánica no era capaz de mantener una guerra ofensiva, o una resistencia decidida, contra más de dos contendientes a la vez. La inactividad militar durante diversos periodos de la Guerra de Restauración portuguesa, hasta la paz con Francia (1659), y la definitiva paz con Portugal para poder atender los asuntos de Flandes durante la Guerra de Devolución (1668), corroboraban esa idea, muy conocida y extendida.

En esos momentos la diplomacia francesa conocía muy bien esa premisa, e intentaba por todos los medios repetirla. Los términos ofrecidos y la alianza sugerida fueron cambiando y transformándose. En esos momentos el fin perseguido ya no era que Portugal se sumase a la causa del Rey Sol en su lucha contra Holanda a cambio de que el imperio colonial luso pudiese recuperar parte del esplendor perdido, sino que las negociaciones francesas pretendían que directamente se declarase la guerra a España. Para ello intentaban forzar la lucha, demonizando al enemigo común, al que los franceses acusaban de estar detrás de la conjura acaecida en 1673 e intentaban hacer creer a los portugueses que las prevenciones militares en Castilla no tenían como objetivo el frente catalán, dejando en el aire la posibilidad irreal de un ataque preventivo ${ }^{54}$, algo a lo que ayudaba el hecho de que los franceses conocían las intenciones hispanas, ya que en suelo castellano eran capaces de interceptar los pliegos enviados desde Lisboa ${ }^{55}$.

Desde su llegada a Lisboa el Abad de Masserati siempre había opinado que Portugal nunca se empeñaría en romper la Paz ${ }^{56}$. De hecho, los documentos capturados por espías e informadores hispánicos advertían que la diplomacia portuguesa en París daba largas a las sugerencias francesas. Mientras tanto París intentaba incidir en que «los castellanos violaron la paz con la perfidia de la conspiración intentada en Lisboa», por lo que una guerra dejaría las cosas claras, a la vez que permitiría una paz general entre todos los príncipes de Europa. Los portugueses intentaban zafarse de las presiones francesas alegando los padecimientos de los 28 años de guerra y la necesidad de juntar las Cortes para poder hacer alguna leva de tropas e intentar aumentar los subsidios militares ${ }^{57}$. A pesar de los informes, a mediados de 1675 el Abad de Masserati ya no parecía tan convencido de la neutralidad portuguesa. Los miedos españoles se cimentaban en que los intereses de ambas naciones eran inseparables, por lo que los subsidios ofrecidos por Francia, junto con las concesiones de las últimas cortes lusas, po-

54 Consulta del Consejo de Estado, 16 de marzo de 1675. AGS, E, Leg. 2.629 f. 27.

55 Consultas del Consejo de Estado, 17 y 27 de abril de 1675. AGS, E, Leg. 2.629 f. 43 y 50.

56 A comienzos de ese año escribía «no se aventurarán a este arrojo». Carta del Abad de Masserati, Lisboa, 18 de febrero de 1675. AGS, E, Leg. 2.629 f. 30.

57 Carta del Abad de Masserati, Lisboa, 23 de febrero de 1675. Copia de la carta del Secretario de Estado de este príncipe, escrita a Duarte Ribeiro, su residente en París, 22 de diciembre de 1674. Copia de la carta de Duarte Ribeiro, París, sin fecha. AGS, E, Leg. 2.629 f. 28, 29 y 31. 
drían tentar a los portugueses a arriesgarse en una guerra. Además, se reforzaban las plazas del Alentejo, reclutando su infantería y remontando la caballería, lo que presagiaba lo peor. Por ello algunos ministros alarmados por los movimientos franco-lusos reclamaban el envío de refuerzos a la frontera y el llamamiento de las milicias, a lo cual el Consejo de Estado se negó para eludir cualquier suspicacia lusa $^{58}$.

Las dudas hispanas - pese a la crisis de confianza - no tardaron en ser resueltas positivamente, gracias a que el Consejo de Estado portugués votó de manera rotunda su no implicación en la guerra, cuya noticia fue pronto conocida en España. La resolución portuguesa fue unánime, y cinco de los seis miembros del consejo eran partidarios de no inmiscuirse en el enfrentamiento entre España y Francia, y pensaban que se debía contestar a Luis XIV con buenas palabras, aunque desengañándole de tal asunto. El único que mostraba más ambigüedad era el Duque de Cadaval — que afirmaba que «Francia era la única monarquía que hoy florecía en Europa»- por lo que era de la opinión de dar a los franceses alguna esperanza de ser socorridos y de divertir a los españoles en la frontera para conservar así su amistad ${ }^{59}$. La contestación portuguesa a Francia fue ciertamente más abierta y menos tajante de lo que realmente pensaban los consejeros lusos, que aunque advertían que no abrirían un nuevo frente contra España, agradecían los apoyos franceses y sus socorros del pasado ${ }^{60}$. La respuesta del gobierno no agradó a algunos sectores, y en julio el juez municipal y los delegados de los gremios de Lisboa se presentaron en la embajada francesa con la intención de reafirmar la amistad portuguesa hacia Francia, acusando a algunos ministros de ser partidarios de España. Quizá la aristocracia portuguesa en esos momentos estaba pecando nuevamente de ambigüedad, ante los lazos que la unían con España, aunque entre los fidalgos las cosas parecían más claras ${ }^{61}$.

El conocimiento de todas estas cuestiones, y las conversaciones mantenidas por Masserati con el Marqués de Fronteira -en las que se reconocía que el príncipe Pedro no daría oídos a los tambores de guerra franceses-, ayudaron a calmar los temores hispánicos. En pro de mejorar las relaciones Masserati recomendaba al Consejo de Estado que al salir de su minoría de edad el rey debería ratificar la Paz de Lisboa, lo que calmaría a los portugueses. Como venía siendo

58 Carta al Marqués de la Mejorada, Madrid, 16 de marzo 1675. Consultas del Consejo de Estado, 16 de marzo de 1675 (hay dos). Copia de la Carta del Maestre de Campo General don Denis de Melo a Secretario de Estado de este Príncipe, Villaviciosa (Portugal), 27 de enero de 1675. AGS, E, Leg. 2.629 f. $26,27,32$ y 49 .

59 Consulta del Consejo de Estado, 7 de mayo de 1675. Carta del Abad de Masserati, Lisboa, 15 de abril de 1675. Copia del memorial que Monsieur de Abbebile presentó a este príncipe, Lisboa, 6 de marzo de 1675. Copia del asiento del Consejo de Estado que se tuvo en primero de abril de 1675 en que se vio el memorial que el enviado de Francia dio a este príncipe en 6 de marzo del mismo año. AGS, E, Leg. 2.629 f. 58, 59, 60 y 61.

60 Copia de la respuesta que el secretario de Estado (de Portugal) dio a Monsieur de Abbevile en 3 de abril de 1675. AGS, E, Leg. 2.629 f. 62.

61 GODINHO, 1990, 295/296. 
habitual el pasado de unión creaba continuas incertidumbres y quejas en Portugal. Hechos como el que un magistrado de Amberes había quitado el hábito de Cristo a un portugués alegando que Carlos II era el único que tenía potestad para concederlo, no dejaban de empañar las relaciones bilaterales ${ }^{62}$.

La tranquilidad española no duró mucho tiempo. Por un lado estaba el miedo del príncipe Pedro al resurgir de una conjura alfonsista en la que podría estar implicada España, ante el apresamiento de un castellano en Sintra, el cual pretendía hablar con el rey, y el posterior encarcelamiento de dos criados del monarca ${ }^{63}$. Pero el gran motivo de preocupación para España era el reforzamiento del ejército portugués, y el incremento de su armada naval, algo que no pasó desapercibido a los holandeses, que intentaron que el príncipe Pedro explicase el motivo de tan inusitados preparativos bélicos. La contestación no se salió de lo esperado, ya que afirmaba que el único motivo era presidiar las plazas de la frontera para que mantuvieran su dotación, mientras que la Armada portuguesa se aprestaba para luchar contra los musulmanes ${ }^{64}$.

Ciertamente en el plano marítimo preocupaba la situación de Portugal, especialmente en Indias, mostrándose una enorme desconfianza hacia los portugueses y sus designios. En este sentido, en 1675 el Consejo de Estado debió calmar los recelos del de Indias, ya que el segundo pensaba que la Armada portuguesa pretendía atacar a los galeones de la plata. Sin duda la cuestión era grave, y se analizó dicho peligro, aunque el Consejo de Estado descartó tal posibilidad. La idea parecía poco factible, ya que la Armada portuguesa de 8 navíos de porte no parecía lo suficiente fuerte como para desbaratar por el momento a los galeones. Tampoco parecía que ese fuera el propósito portugués, determinándose que las sospechas del Consejo de Indias eran exageradas ${ }^{65}$.

Independientemente de los miedos y prevenciones del Consejo de Indias, lo que era cierto es que los portugueses habían reforzado y modernizado su Armada. En esos momentos se componía de 8 navíos de porte -7 de ellos con más de 40 piezas de artillería-, estando en construcción en Oporto otro de dichas características, y además disponía de un patache auxiliar ${ }^{66}$. La noticia de que dicha Armada se aprestaba con rumbo incierto hizo sonar todas las alarmas. Esto reafirmaba la nueva idea del Consejo de Estado de que el príncipe de Por-

\footnotetext{
62 Consultas del Consejo de Estado, 8 de mayo 1675 (dos de la misma fecha). Carta del Abad de Masserati, Lisboa, 15 de abril de 1675. AGS, E, Leg. 2.629 f. 62,65 y 64

63 Consultas del Consejo de Estado, 16 y 25 de mayo, y 27 de junio de 1675. AGS, E, Leg. 2.629 f. 70,68 y 72 .

64 Consulta del Consejo de Estado, 22 de julio 1675. Carta del Abad de Masserati, Lisboa, 1 de julio 1675 (hay dos de la misma fecha). Copia de la carta de los Estados Generales de las Provincias Unidas al príncipe regente de Portugal, 29 de abril de 1675. AGS, E, Leg. 2.629 f. 79, 80, 88 y 81.

65 Consulta del Consejo de Estado, 28 de septiembre 1675. AGS, E, Leg. 2.701.

66 Copia de la carta del Abad don Juan Domingo Masserati escrita al Marqués de la Laguna, 1 de julio de 1675. Relación del porte y trozo de los navíos de guerra de la Armada portuguesa, sin fecha. AGS, E, Leg. 2.629 f. 89 y 90.
} 
tugal había ajustado el casamiento de su única hija con un príncipe de sangre francés, y por ello quizá se estaba aprestando dicha Armada, teniéndose por cierto que los portugueses declararían la guerra a España en la primavera siguiente. Por ello la resolución del Consejo de Estado indicaba que se escribiera a la corte inglesa y a Holanda para saber si conocían el destino final de la escuadra $^{67}$. La respuesta de La Haya no tardó en producirse, aunque ésta generaba más incertidumbres y miedos, ya que los holandeses corroboraban que el apresto de la Armada se había pagado con dinero francés, siendo su destino más seguro apoyar las operaciones navales en el Mediterráneo o atacar a los holandeses en Guinea, pensándose que podrían juntarse con la Armada francesa y atacar los galeones de la plata ${ }^{68}$.

La rápida llegada de los informes de Masserati difuminaron en parte los temores, al conocer éste las instrucciones dadas a la Armada, que en principio tenía como destino recorrer las costas norteafricanas y luchar contra los musulmanes, además de traer de Saboya a un pariente de la princesa de Portugal que se casaría con la infanta heredera ${ }^{69}$. Pero ciertamente preocupaba en España el silencio con el que se llevaba la operación incluso en Lisboa, "causando allí grande embeleso en todos el no saberse el fin de esta expedición, por parecer extraño que se haya hecho un gasto tan grande solo para bizarrear contra moros...", como decía Masserati, además de que sorprendía el gran número de infantería veterana que se estaba embarcando, y que ya el coste de la operación sobrepasaba el millón de cruzados. El destino de la Armada era incierto incluso para los propios lisboetas, por lo que algunos se aventuraban a sumar a las posibilidades anteriores dos nuevos destinos, como traer de vuelta a Portugal a la reina de Gran Bretaña o a otro candidato para el matrimonio de la infanta, un hijo segundo del Gran Duque de la Toscana ${ }^{70}$.

Las incertidumbres continuaron durante algunas semanas más, causando el avistamiento de la escuadra portuguesa en el estrecho de Gibraltar pánico entre las autoridades locales españolas ${ }^{71}$, temiéndose incluso que pudieran atacar Ceuta $^{72}$ o que su destino fuese auxiliar a las tropas francesas en el Mediterráneo. Dichas sospechas se agudizaron al reconocerse que la armada portuguesa ha-

67 Consulta del Consejo de Estado, 4 de agosto de 1675. AGS, E, Leg. 2.629 f. 95.

68 Carta de don Manuel de Lira, La Haya, 3 de septiembre de 1675, (recibida en Madrid el 20 de septiembre). AGS, E, Leg. 2.629 f. 148.

69 Cartas del Abad de Masserati, Lisboa, 8 y 28 de julio 1675. Consulta del Consejo de Estado, 4 de agosto de 1675 (otra de la misma fecha). AGS, E, Leg. 2.629 f. 93, 95 y 92.

70 Cartas del Abad de Masserati, Lisboa, 22 de julio de 1675. AGS, E, Leg. 2.629 f. 98.

71 Prevenciones para España y África por salir un trozo de la Armada de Portugal con intención de recorrer la Berbería, Madrid, 2 de septiembre de 1675. AGS, GA, Libro 329 f. 172 y 174.

72 De hecho se ordenó un envío urgente de 400 infantes para reforzar Ceuta. Orden del Consejo de Guerra, 19 de agosto de 1675. AGS, GA, Libro 329 f. 168v. Respuesta a la carta del Conde de Torresvedras de 17 del pasado avisándole lo dispuesto para la prevención de aquella plaza, Madrid, 19 de agosto de 1675. AGS, GA, Libro 305 s/f. Consulta del Consejo de Estado, 20 de septiembre 1675. AGS E, Leg. 2.629 f. 130. 
bía apresado a una saetía de Ceuta, aunque se debiera a que una de Gibraltar había hecho lo mismo con un navío portugués. Pero el destino final de la Armada no se conoció hasta que ésta arribó a Alicante ${ }^{73}$, debido a que los mandos portugueses tenían la orden de abrir sus despachos en ese momento ${ }^{74}$, miedo a lo que también influía la orden dada por el príncipe Pedro de que a la altura de Gibraltar utilizaran banderas francesas.

El fin de la Armada portuguesa fue atacar las posiciones musulmanas en el norte de África, y en el mes de septiembre, tras recorrer la costa, asaltaron la plaza de Sargel, a unas 16 leguas al oeste de Argel ${ }^{75}$. En total la expedición contó con 11 navíos, al sumarse a la flota portuguesa un navío genovés, teniendo la escuadra un total de 458 piezas de artillería, y llevando 3.610 marineros e infantes, entre los que iban lo más granado de la nobleza portuguesa ${ }^{76}$. El 14 de octubre la flota portuguesa había vuelto ya a Lisboa de su corta y triunfal campaña, desembarcando los voluntarios de alta alcurnia, pagándose a la tropa, y desarbolándose la mayoría de los navíos para pasar el invierno. Con su peculiar acción Portugal había demostrado su capacidad y que seguía siendo un rival a tener en cuenta en el Mediterráneo, al mismo tiempo que asestaba un golpe al corso musulmán, ya que se pensaba por las noticias aportadas por un portugués rescatado de Argel, que a lo largo de ese año los musulmanes habían apresado 23 embarcaciones portuguesas de diversa condición y tamaño. Pero las prevenciones portuguesas continuaban, y se construían otros dos navíos de guerra en la ribera del Tajo ${ }^{77}$. Las acciones marítimas portuguesas - pese a las incertidumbres causadas en Madrid y Ámsterdam-, habían significado más un acercamiento que otra cosa, ya que en el norte de África habían rebajado la presión ejercida sobre España, especialmente en

73 Cartas del Marqués de la Laguna, Puerto de Santa María, 22 de agosto 1675 (dos de la misma fecha). Consultas del Consejo de Estado, 22, 24 y 31 de agosto y 1 de septiembre de 1675. AGS, E, Leg. 2.629 f. 106, 108, 102, 103, 107 y 115 .

74 Copia del regimiento que se dio al general Pedro Jaques de Magallanes cuando salió de esta barra con los 11 navíos de la Armada de este reino, Lisboa, 27 de julio de 1675. AGS, E, Leg. 2.629 f. 112.

75 La plaza tenía según las fuentes portuguesas más de 8.000 vecinos, con un presidio formal de 1.500 infantes turcos y al menos 2.000 cautivos cristianos. Si bien el asalto nocturno no duró más que unas pocas horas, hasta la mañana siguiente, éste debió causar bastantes bajas. A continuación la ciudad fue saqueada y sus fortificaciones derruidas, pudiéndose capturar un botín que ascendía a seis millones de cruzados: Relación verdadera de la toma, y asalto de la Ciudad de Zargel, y su Presidio, por las Armas de Portugal, en Setiembre del año de 1675, Cádiz, 1676, Impreso por Juan Vejarano.

76 Relación del porte de los once navíos de guerra de la Armada de Portugal, sin fecha. AGS, E, Leg. 2.629 f. 114 (2). Según los impresos portugueses la Armada consistía en 12 navíos, la mayoría con mucho más porte y cañones que lo que informaban las fuentes españolas, que conducía a más de 9.000 hombres, sin duda una exageración. Si bien es posible que fueran más de los 3.600 hombres que estimaban los españoles, al embarcarse varias unidades posteriormente en el Algarbe, los 12 barcos no eran lo suficientemente grandes como para llevar tantos hombres, por lo que sin duda lo Impreso de Juan Vejarano en Cádiz contribuía más a los fines portugueses, que pretendían acreditarse como una potencia militar a tener en cuenta en el Mediterráneo.

77 Carta del Abad de Masserati, Lisboa, 14 de octubre de 1675. Consultas del Consejo de Estado, 31 de octubre, 28 de noviembre y 12 de diciembre de 1675. AGS, E, Leg. 2.629 f. 154, 153, 163 y 169. 
Orán, plaza que en esos momentos se encontraba bajo sitio ${ }^{78}$. De hecho, Portugal llegó a insinuar su colaboración, la cual nunca se llevó a cabo ante la falta de una petición formal por parte de España. Algo que para los portugueses no dejaba de ser un signo evidente de lo altivos que eran los castellanos, que antes de doblar su rodilla y formular su petición estaban dispuestos a perder Orán ${ }^{79}$.

Mientras tanto, los franceses intensificaban sus esfuerzos en Lisboa con la llegada de un nuevo embajador, sumándose a ellos un enviado sueco. Ya la semántica de sus negociaciones parece que había cambiado, y a pesar del positivismo y el reparto de ocasiones previas, la llegada del francés surgía al mismo tiempo que el rumor de que venía a reclamar todos los fondos suministrados durante la pasada Guerra de Restauración, los cuales ascendían a unos 4 millones de cruzados. La entrada del nuevo ministro francés empezó con mal pie ante su embarazo con el tribunal de la inquisición, pero su rápida audiencia con la princesa no dejó dudas de su ímpetu por conseguir lo que los anteriores no habían logra$\mathrm{do}^{80}$. Su interés por contactar con la princesa era lógico, ya que desde su llegada a Portugal ${ }^{81}$, María Francisca de Saboya Nemours ${ }^{82}$ y su séquito ayudaron al mantenimiento de una política pro francesa, actuando siempre como un satélite de opinión a favor de los intereses galos. Su impronta era tal que en 1674 Mariana de Austria presionó para que el Duque de Saboya cambiase a su representante en Madrid, ante su vehemente correspondencia con la princesa y su confesor, algo que excedía su comisión, «manifestando una desordenada passión a las cosas de Francia», lo que estaba perjudicando a la causa española y su buen entendimiento con Saboya ${ }^{83}$.

A finales de 1675 las instrucciones del representante francés, Monsieur de Guénégaud, fueron también interceptadas por Masserati y sus informantes, a los que daba fuertes cantidades de dinero a cargo de los gastos secretos. Lo cierto es que las instrucciones nada decían de la restitución de los fondos entregados a Portugal en el pasado, a lo cual hizo hincapié el marqués de Fronteira —uno de los validos del príncipe Pedro- en su entrevista privada con Masserati, acusando a los españoles como difusores de ese bulo por Lisboa ${ }^{84}$. Las instrucciones, más que reclamar o pedir la devolución de dinero, lo que sí hacían era informar del dinero que Francia se debía gastar en pensiones y subsidios para sus afectos en la

78 Ya a principios de año se había barajado la posibilidad de que navíos portugueses colaborasen con los españoles para limpiar las costas de corsarios musulmanes. Consulta del Consejo de Estado, 25 de enero de 1675. AGS, E, Leg. 2.629 f. 10.

79 Carta del Abad de Masserati, Lisboa, 22 de julio de 1675. AGS, E, Leg. 2.629 f. 98.

80 Carta del Abad de Masserati, Lisboa, 2 de diciembre de 1675. Consultas del Consejo de Estado, 22 de noviembre, 7, 10, 12 y 31 de diciembre de 1675; y 9 de enero de 1676. AGS, E, Leg. 2.629 f. 175 , 159, 165, 164, 169 y 172; y Leg. 2.630 f. 1.

81 Consulta del Consejo de Estado, 23 de julio 1669. AGS, Estado Leg. 2.615.

82 BENEVIDES, 1879 2. DRUMOND BRAGA, 2011.

83 Carta de Mariana de Austria al Príncipe de Ligne, Madrid, 30 de octubre de 1674. AGS, Estado Leg. 2.629.

84 Carta del Abad de Masserati, Lisboa, 2 de diciembre de 1675. AGS, E, Leg. 2.629 f. 175. 
corte lusa, y de las cantidades que se donarían en caso de que Portugal atacase a España: entre 600.000 y 800.000 escudos de plata en moneda portuguesa. La visión francesa interpretaba la paz con España como un grave perjuicio para Portugal, y acusaba a los lusos de que se habían olvidado muy pronto de la conjura de Humanes. A su vez pintaba a sus enemigos como derrotados y se hacía eco de la grandeza de Francia y de sus recientes conquistas, intentado mostrar a los portugueses que lo mejor era apostar por el ganador y aventurarse cuanto antes a una alianza, llegando a afirmar «conviene mucho para la conservación y aumentación a su monarquía declararse por el partido de Francia». Para llegar a ese convencimiento lo primordial era «reducir al príncipe a abrazar el partido de la Francia», para lo cual se debían buscar a las personas más apasionadas que pudieran apoyar tal opción. Entre ellos destacaban el Duque de Cadaval y su esposa, los cuales recibían fuertes sumas en concepto de pensiones ${ }^{85}$, advirtiéndose que debían conseguir que la princesa ejerciese sus influencias y que no se ladease hacía los intereses portugueses. Otros personajes afines a la causa podrían ser el hijo del difunto Marqués de las Minas, al que se debía captar, a la vez que se mantendría gran disimulo de todos estos negocios con el Marqués de Fronteira por reconocerse que éste era contrario a los intereses franceses ${ }^{86}$.

El príncipe Pedro parecía poco receptivo a las insinuaciones francesas, pese a que en esos momentos la comunidad francesa en Lisboa era cada vez mayor, como afirmaban las crónicas españolas, que acusaban a éstos de que no «ahorraban el veneno con divulgar que las apariencias de amistad de Castilla son engañosas». En cambio, el pueblo llano parecía más contento con el mantenimiento de la paz, lo cual desengañaba a los franceses y tranquilizaba a los españoles, que estaban más pendientes de los movimientos de los ministros portugueses filofranceses que de los sucesos de la propia corte ${ }^{87}$. De hecho, la noticia enviada por el elector de Brandemburgo reconociendo que se estaba ajustando una alianza entre franceses, suecos y portugueses, no afectó la tranquilidad de Masserati, que contestó al Consejo de Estado por carta diciendo que tenía «noticia de que el príncipe está con firmeza en el dictamen de conservar la paz con nosotros». Distinto parecer mantenía de la Princesa, de la que decía que tenía más parte y manejo de los negocios que por lo pasado, lo cual no dejaba de ser peligroso ${ }^{88}$. De hecho durante todo ese año los informes de Masserati incidían en el hecho de que la princesa ejercía una notable influencia en la Corte, y que con ayuda del Duque de Cadaval había aumentado el número de sus partidarios entre los indiferentes, y

85 Según los informes de Masserati, éste, aunque muy rico, era codicioso, por lo que se daba por válido que sería tentado con facilidad por los franceses. El duque se había casado en segundas nupcias con la francesa María Angélica de Lorena, hija del Conde de Harcourt.

86 Consulta del Consejo de Estado, 16 de enero 1676. Instrucción que debe usar el Sr. Guinegaud mi enviado extraordinario al príncipe regente de Portugal, Saint-Germain en Laye, 8 de julio de 1675, Luis Arnauld de Pomponne. AGS, E, Leg. 2.630 f. 4 y 5.

87 Carta del Abad de Masserati, Lisboa, 20 de enero 1676. Consultas del Consejo de Estado, 5 y 11 de marzo de 1676. AGS, E, Leg. 2.630 f. 9, 24 y 26.

88 Consulta del Consejo de Estado, 19 de marzo de 1676. AGS, E, Leg. 2.630 f. 30. 
muchos «por no desagradarla, visten los colores de su librea, templando las velas al ayre de la contemplación». Mientras tanto, el partido francés estaba siempre atento para malquistar y hacer que los portugueses desconfiaran de los españoles ${ }^{89}$.

Si bien el enviado español en Lisboa había sido meridiano en sus avisos, y tenía clara la intención del regente Pedro, los hechos no coincidían con la tranquilidad y las palabras que llegaban desde el país vecino. La información recibida era en gran medida contradictoria, y entre marzo y mayo no pararon de llegar preocupantes noticias que hablaban de un significativo aumento de las fuerzas lusas presentes en la frontera. Aprestos que parecían indicar una movilización total y no sólo el refuerzo fronterizo ${ }^{90}$. En muchas plazas de frontera se estaban realizando importantes obras de fortificación, las cuales se extendían incluso al estuario del Tajo, lo que para muchos significaba que las instancias del ministro francés para que Lisboa declarase la guerra iban por buen camino, y la ruptura era inminente ${ }^{91}$ Tales hechos eran inciertos, y aunque con una parte de realidad, como rumores de frontera se habían propagado como la pólvora causando numerosos problemas y miedos. Lo cierto era que los aprestos hacían referencia a que los Tercios de ordenanza portugueses se estaban reuniendo para que la milicia practicase con sus armas, y las órdenes sólo insistían en la formación de varios Tercios auxiliares que se crearon en tiempo de la guerra, todo ello muestra del celo de algunos de los mandos fronterizos portugueses. En cuanto a la caballería, sí que se había aprobado su aumento, aunque en mucho menor número que en las previsiones iniciales, organizándose tres compañías de caballería a cargo de los mercaderes de Lisboa, las cuales se agregaron al regimiento de caballería del Duque de Cadaval que permanecía en Lisboa ${ }^{92}$.

Los españoles no podían realizar despliegue alguno de tropas en la frontera para contrarrestar los movimientos portugueses, idea que incluso fue desechada desde el primer momento, postulándose la teoría que lo mejor era no herir la susceptibilidad portuguesa. En las pocas levas que durante ese año se extendieron por la frontera se ordenó que se anduviera con pies de plomo en tales asuntos, estableciéndose que los cuerpos de guardia — como el dispuesto en Zamora- no mantuvieran a muchos soldados, dándose orden para que éstos se condujeran en pequeñas tropas a otras zonas tierra adentro, facilitándose siempre la noticia de que las levas eran para Cataluña ${ }^{93}$. De hecho esta cuestión se volvió a repetir al

89 Carta del Abad de Masserati, Lisboa, 29 de junio de 1676. AGS, E, Leg. 2.630 f. 100.

90 El Gobernador de las Armas de la frontera de Sevilla avisó que en esa zona se estaban formando 13 Tercios de 4.500 hombres y se quintaban los lugares, mientras que la caballería se remontaba y estaba pronta para actuar.

91 Consultas del Consejo de Estado, 26 de marzo y 16 de abril de 1676. AGS, E, Leg. 2.630 f. 34 y 42.

92 Consultas del Consejo de Estado, 7, 12 (dos de esa fecha), 24 y 30 de mayo; 17 y 24 de junio de 1676. Carta del Abad de Masserati, Lisboa, 25 de mayo de 1676. AGS, E, Leg. 2.630 f. 52, 53, 54, 63, $65,73,78$ y 88.

${ }_{93}$ Consulta del Consejo de Estado, 23 de abril de 1676. AGS, E, Leg. 2.630 f. 46. 
año siguiente, insistiéndose en las mismas órdenes ${ }^{94}$. Los españoles no querían causar más incertidumbres y sospechas, por lo que en ese mismo año se determinó que el Marqués de Frejenal, titulado portugués que tras la conjura de 1673 había cruzado la frontera para refugiarse en España -habiéndosele confiscado su hacienda en Portugal-, no recibiría los 3.000 reales de mesada y 1.000 ducados de ayuda de costa para traer su casa a Castilla, cantidades que se fijaban para todos los titulados portugueses que habían ofrecido su fidelidad a los Austrias. El Consejo de Estado no quería que al recibir dicha pensión se presupusiera que España había tenido algo que ver con la conjura, por lo que se rechazaba su pensión al mismo tiempo que se le contestaba ambiguamente con la fórmula de que el rey tendría presente sus méritos ${ }^{95}$. De hecho esta clase de fugas al otro lado de la frontera era una tónica habitual entre ambos bandos, ya que al caer Valenzuela varios titulados españoles se pasaron a Portugal ${ }^{96}$.

\section{LA MEDIACIÓN LUSA EN NIMEGA Y EL CAMINO HACIA LA COLABORACIÓN}

Durante los meses siguientes los intereses lusos bascularon más hacia la intermediación y la colaboración que hacia la guerra con España, aunque el uso del miedo a ésta última nunca se descartó como pieza clave dentro del juego político. Por un lado - y a instancias del ministro portugués en París, Duarte Ribeiro ${ }^{97}$ - el príncipe Pedro mostró un creciente interés en participar en el congreso de Nimega, con la intención de «gozar de la paz que tenía con toda Europa» ${ }^{98}$. La idea de la intermediación sobre los príncipes guerreantes que combatían en Europa tuvo el claro apoyo del Consejo de Estado portugués ${ }^{99}$, y pronto todos los esfuerzos diplomáticos lusos se centraron en dicha cuestión, pidiéndose apoyo al rey de Inglaterra ${ }^{100}$, y consiguiendo meses después la aceptación de Holanda ${ }^{101}$. La mediación hubiera hecho que Portugal se situase en la primera línea de la política internacional europea, siendo ello un claro impulso para sus aspiraciones europeístas. Dicho ofrecimiento fue acogido con mucha tibieza en el resto de cancillerías europeas, ante la clara falta de influencia de Portugal, sus escasos argumentos de arbitraje y su propio aislamiento, ya que a ojos de algunos de los contendientes su neutralidad no parecía suficiente. Muchos consejeros de estado se manifestaron contrarios a tal interposición, ya que

94 Orden Real, Buen Retiro, 14 de febrero de 1677. AGS, E, Leg. 2.631.

55 Consulta del Consejo de Estado, 6 de mayo de 1676. AGS, E, Leg. 2.630 f. 51.

96 LORENZO PINAR y VASALLO TORANZO, 2001, 147.

97 Sobre su quehacer diplomático: LEAL DE FARIA, 2007.

98 Copia de la respuesta que de orden de este príncipe dio el Secretario de Estado a la carta de 14 de marzo pasado de Duarte Ribeiro su residente en París. AGS, E, Leg. 2.630 f. 66.

99 Consulta del Consejo de Estado, 14 de septiembre de 1676. AGS, E, Leg. 2.630 f. 121.

100 Carta del Abad de Masserati, 26 de octubre de 1676. Copia de la carta de don Francisco de Melo, embajador de Portugal en Londres, escrita por el secretario de estado Francisco Correa de la Cerda, 14 septiembre de 1676. AGS, E, Leg. 2.630 f. 149 y 150.

101 Consulta del Consejo de Estado, 22 de abril de 1677. AGS, E, Leg. 2.631. 
interpretaron que los portugueses estarían demasiado cerca de las tesituras francesas, por lo que nunca podrían ser imparciales. Pese a ello, España siempre intentó dilatar su resolución de apoyo formal al plan, con la esperanza de que los lusos pronto se desengañaran, sin que en el país vecino esto se pudiera interpretar como un signo de desprecio ${ }^{102}$.

Los intentos de mediación en el Congreso de Nimega llegaban en un momento que no carecía de tensión para España. Por un lado, los intentos lusos de encontrar un pretendiente para la hija del príncipe Pedro, Isabel Luisa, no dejaba de ser un motivo de desestabilización, ya que a lo largo de esos meses se barajaron varios candidatos en la Toscana, Baviera y Francia, preocupando mucho que la princesa se casara con el Delfín, algo que nunca llegó a producirse ante la negativa lusa a la unión de ambas coronas ${ }^{103}$. Pero sin duda era todavía más preocupante y desestabilizadora la orden portuguesa de que los gobernadores de todas las fronteras asistieran a sus provincias, abandonando la Corte, y tuvieran preparada a toda la gente de guerra. Las palabras de Masserati resumían bastante bien este ambiente, ya que escribía a Madrid alegando lo difícil que era averiguar «el verdadero motivo de estas disposiciones, y si son efectos de precaución nacida de la desconfianza inseparable de los naturales de estos hombres, o de algún aviso bago o supuesto por la industriosa malicia de nuestros enemigos y parciales de Francia para conmober a recelo de estos ánimos, fáciles del suyo, a la credulidad e impresiones». Una parte del problema podía ser las ambiciones de algunos mandos del ejército portugués, que gracias a ello intentaban aumentar el número de fuerzas de sus provincias y por ende su propia importancia ${ }^{104}$. Ante todo, lo cierto es que no dejaba de estar a la orden del día el claro interés luso por reforzar su ejército, y con ello sus ventajas políticas frente a España.

El proyecto de mediación luso fue un quebradero de cabeza para España durante la primera mitad de 1677. A comienzos de mayo los portugueses habían conseguido la aceptación de Francia, Holanda, Gran Bretaña y el Papado, pero la respuesta española ya se demoraba 9 meses provocando un profundo malestar entre las filas lusas. En esos momentos la política portuguesa se debatía hacia dos extremos opuestos, la paz con España por medio de la mediación en Nimega, y la guerra, que conllevaría la consecuente alianza con Francia. El silencio español había conseguido que el ministro francés en Lisboa consiguiera importantes argumentos, y que hablase de la injuria que Portugal sufría a vista de toda

102 Carta del Abad de Masserati, 3 de agosto de 1676. Consulta del Consejo de Estado, 29 de agosto de 1676. Carta del Príncipe Pedro, Lisboa, 3 de agosto de 1676. AGS, E, Leg. 2.630 f. 189, 191 y 193. Consulta del Consejo de Estado, 25 de enero 1677. AGS, E, Leg. 2.631.

103 Cartas del Abad de Masserati, Lisboa, 20 y 23 de julio de 1676 (dos de esa última fecha). Consultas del Consejo de Estado, 8 y 19 de agosto, y 23 de septiembre de 1676. Copias de las cartas del Secretario de Estado a Duarte Ribeiro, 15 de junio y 7 de julio 1676. Copia de la respuesta que hizo el padre Antonio de Vieira al Gran Duque de Toscana en 3 de marzo de 1676. Copia del capítulo de carta que don Baltasar de Fuenmayor escribió al Sr. Marqués de los Balbases y remitió al Abad de Masserati, con carta del 5 de septiembre de 1676. AGS, E, Leg. 2.630 f. 107, 108, 113, 104, 114, 124, 109, 111, 112 y 119.

104 Carta del Abad de Masserati, Lisboa, 8 de febrero de 1677. AGS, E, Leg. 2.631. 
Europa ${ }^{105}$. Incluso en Lisboa empezaron a circular impresos y panfletos que intentaban crear una opinión favorable a evitar la neutralidad y al rompimiento de la paz con España ${ }^{106}$, textos que al parecer se habían impreso en Francia y se divulgaban a través de los franceses presentes en dicho reino ${ }^{107}$.

Mientras tanto, los recelos mutuos en la frontera continuaron, realizándose levas en Portugal e importantes reparaciones en sus fortificaciones. Comenzaron a reclutarse cuatro nuevos Tercios en Lisboa, Setúbal y Cascáis, cada uno de entre 1.400 y 1.500 hombres, al mismo tiempo que se llamaba a los soldados de los Tercios auxiliares y los de Ordenanza. También se aumentó la caballería al obligar a los mercaderes de caudal de Lisboa a sustentar a su costa hasta 300 caballos para las 6 nuevas compañías de caballería que se formaban, retrayéndose fondos destinados a pagar los débitos a los asentistas y otros ingresos provenientes de los derechos de la sal para financiar todo el despliegue militar ${ }^{108}$. Al mismo tiempo en Extremadura se realizaban levas para el frente catalán, lo que lógicamente ocasionaba las quejas portuguesas. Sumándose a todo ello los contratiempos ocasionados por el contrabando y la introducción de oro y plata de manera ilegal por la porosa frontera ${ }^{109}$, y los roces fronterizos entre ambas comunidades, ante el maltrato de unos portugueses que pescaban en la ribera del Caya en Extremadura ${ }^{110}$.

En mayo de 1677 por las calles de Lisboa se hablaba abiertamente de que habría una guerra en vista de las prevenciones militares, pero en Madrid, tras conocerse la noticia, el Consejo de Estado sólo pudo limitarse en su resolución a afirmar que el estado de la Real Hacienda era tan notorio que no podía suministrarse nada para la frontera ${ }^{111}$. Esto dejaba la puerta abierta a la aceptación española de la mediación, pero el despliegue militar luso desataba numerosas dudas y viejos miedos, como la posibilidad de que se introdujeran nuevas pretensiones lusas sobre algunos puntos del Tratado de Paz de 1668 o sobre la restitución de Ceuta ${ }^{112}$, plaza que ya había desatado tensiones bilaterales a lo largo de los 10 años de paz ${ }^{113}$.

De hecho los portugueses establecieron un verdadero ultimátum, afirmando que si el día 15 de junio no obtenían una respuesta positiva a la mediación se da-

105 Carta del Abad de Masserati, Lisboa, 9 de mayo de 1677. Traducción del papel del Secretario de Estado Francisco de Correa de la Cerda escrito al Abad de Masserati, Lisboa, 8 de mayo de 1677. Consulta del Consejo de Estado, 17 de mayo de 1677. AGS, E, Leg. 2.631.

106 Advertencia que un ministro del Príncipe don Pedro le hace sobre el estado presente del reino de Portugal, 1677. Consulta del Consejo de Estado, 20 de mayo de 1677. AGS, E, Leg. 2.631.

107 Carta del Abad de Masserati, Lisboa, 3 de mayo de 1677. Consulta del Consejo de Estado, 10 de junio 1677. AGS, E, Leg. 2.631.

108 Cartas del Abad de Masserati, Lisboa, 17 y 23 de mayo de 1677. AGS, E, Leg. 2.631.

109 Carta del Abad de Masserati, Lisboa, 19 de marzo de 1677. Consultas del Consejo de Estado, 8 de febrero, 3 y 27 de abril de 1677. AGS, E, Leg. 2.631.

110 Carta del Abad de Masserati, Lisboa, 19 de mayo de 1677. Carta del Conde de Charny, Badajoz, 17 de abril de 1677. Consultas del Consejo de Estado, 6 y 20 de mayo de 1677. AGS, E, Leg. 2.631.

111 Consultas del Consejo de Estado, 1 de mayo de 1677. AGS, E, Leg. 2.631.

112 Copia de la Carta del Abad de Masserati, Lisboa, 23 de mayo de 1677. AGS, E, Leg. 2.631.

113 Consulta del Consejo de Estado, 29 de enero de 1673. AGS, E, Leg. 2.695. Sobre estas cuestiones también: RODRÍGUEZ HERNÁNDEZ, 2011: 107-108. 
rían por respondidos, dejando en el aire la posibilidad de cualquier acción. No parece que esto fuera un mero ardid diplomático, ya que tuvo su eco en la frontera. En junio llegaron al Consejo de Guerra noticias muy preocupantes desde Galicia, que indicaban que en Villanova de Cerveira había al menos 600 infantes portugueses que públicamente decían que si no se concedía lo pedido atacarían la frontera. Si al final esto sucedía sería un verdadero desastre, ya que podrían ocupar con facilidad las plazas fronterizas del reino por lo desprevenidas que estaban ${ }^{114}$.

Más allá del lenguaje cortesano, una relación de los sucesos de la época nos detalla el acontecimiento y el sentimiento que causó en Madrid el proyecto mediador portugués, y las dudas y el desprecio que causó en el Consejo de Estado. En primer lugar se denominaba a la dinastía Braganza como intrusos y rebeldes, fundamentándose la queja española en que el príncipe Pedro había atravesado la línea de las apariencias y pretendía ser "concertador de monarquías quando la que oy goça, es tan contra derecho y sucesión, conseguida y lograda en la monstruosa menor edad de un Rey niño». Queja española a la que sumaba la elección como plenipotenciario portugués de Don Francisco de Melo, «sujeto nada capaz y demás que Bastante sospecha para España». Aderezándose todo ello con la recurrente idea, claramente fuera de lugar, de que Portugal podría volver a la órbita española, y que los Braganza serían castigados ${ }^{115}$.

Es difícil interpretar el órdago portugués, y el ultimátum formulado. Por un lado Portugal sabía las pocas posibilidades españolas de defenderse ante una agresión lusa en la frontera, habida cuenta de su antagónica lucha con Francia y de su progresivo debilitamiento militar, hacendístico y humano. Por ello es lógico que utilizara esa ventaja militar y acudiera a la intimidación, medio que se confirmaría nuevamente como seguro para conseguir sus fines políticos. Incluso el enviado español en Lisboa nos informa de otras cuestiones que también debemos tener en cuenta, las cuales sin duda también tuvieron mucho que ver en todos los acontecimientos. A mediados de ese año expiraba el tratado secreto establecido entre Portugal y Francia 10 años atrás, que aunque incumplido seguía teniendo validez. Es posible que el gobierno luso, consciente de ello, utilizara su proyecto de mediación para evitar la renovación de dicho acuerdo, quitándose así de encima las presiones francesas, artimaña que supo aprovechar muy bien ${ }^{116}$. También los portugueses conocían la delicada situación por la que atravesaba España, sus problemas financieros -no habiendo un real para acudir a las necesidades domésticas, como avisaba Duarte Ribeiro de Macedo-, militares y de reclutamiento. Por ello era lógico que su representante en Madrid se hiciera eco del malestar que generaba en España cual-

114 Carta del Consejo de Guerra al Marqués de Falces, Madrid, 13 de julio 1677. AGS, GA, Libro 341 f. $7 \mathrm{v}$.

115 Diario de todo lo sucedido en Madrid desde el sábado 23 de enero de 1677, que entró Su Alteza el Srmo. S.D. Juan de Austria, llamado de su Majestad, a 15 de julio de 1678, por Juan Antonio de Valencia Idiáquez. BN, Madrid, Ms. 2.289 f. 128-129.

116 Carta del Abad de Masserati, Lisboa, 10 de mayo de 1677. Consulta del Consejo de Estado, 28 de mayo 1677. AGS, E, Leg. 2.631. 
quier noticia sobre el aumento de las defensas en la frontera, y que supiera que el debilitamiento español, y que las pérdidas territoriales en Flandes eran factores a tener en cuenta en cualquier presión diplomática lusa ${ }^{117}$.

Ante la amenaza lusa, la aceptación española a la mediación no tardó en llegar, aunque la justificación portuguesa a dicho ultimátum carecía de suficiente rigor. A los españoles no les faltaba razón cuando alegaban que los portugueses no habían comunicado su proyecto a parte del bando aliado. De hecho tardíamente se le comunicó al Emperador la mediación de una manera indirecta, ya que la débil diplomacia lusa carecía de la suficiente consistencia o representantes en las Cortes centroeuropeas, algo que también ocurría con buena parte de las potencias que actuaban como aliadas de España, como Dinamarca, Cell, Münster u Osnabruck. La aceptación imperial se consiguió gracias a la mediación papal ${ }^{118}$, mientras que el beneplácito mucho más tardío de algunos príncipes electores alemanes se formuló a través del Duque de Villahermosa, Gobernador de los Países Bajos ${ }^{119}$. Todo ello hizo que el mejor apoyo portugués lo obtuviera de España, a pesar de su tardía aceptación, ya que Francia hizo bastante poco por ello. Si bien a mediados de octubre de 1676 Luis XIV aceptaba y agradecía el proyecto, lo condicionaba a la participación sueca, no volviendo a retomar el asunto ${ }^{120}$.

Los esfuerzos franceses realmente iban encaminados a la guerra, ya que la mediación para nada les interesaba. Si Portugal atacaba a España se propiciaría el rápido derrumbe militar hispano en todos los frentes, haciendo que las negociaciones de Nimega fueran mucho mejores para Francia. Por ello los franceses redoblaron sus intentos por conseguir una alianza con Portugal, subiendo su apuesta, al poner sobre la mesa la suma de un millón de cruzados al contado, y otros 500.000 al año durante todo el tiempo que durase la guerra, además de 12 navíos de guerra franceses y la infantería que el príncipe Pedro considerase necesaria. Además, el ministro francés en Lisboa con una excesiva frecuencia se entrevistaba con la princesa ${ }^{121}$ y la nobleza para intentar la persuasión, a pesar de que en muchos ambientes sus instancias eran recibidas con excesiva tibieza. Igualmente se intentaba lo mismo a través de otros agentes, como el confesor jesuita de la princesa, o su médico personal —ambos franceses-, al igual que el cónsul de dicha nación, hombre de gran capacidad. Todos los intentos corrieron la misma suerte, aunque algunos consejeros portugueses parece que cambiaron sus afectos hacia Francia ${ }^{122}$.

117 Copia de las cartas de Duarte Ribeiro de Macedo, enviado de Portugal en Madrid, escritas a Francisco de Correa de la Cerda, Secretario de Estado, desde 18 de noviembre de 1677 a 20 de marzo de 1678. AGS, E, Leg. 2.633 f. 127.

118 Carta del Abad de Masserati, Lisboa, 17 de mayo de 1677. AGS, E, Leg. 2.631.

119 Consulta del Consejo de Estado, 26 de octubre de 1677. AGS, E, Leg. 2.632.

120 ESTRADES, 1743, Tomo VII, 296/297 y 319/320.

121 De ella se decía, "que nunca se desnudará de su inclinación a Francia». Carta del Abad de Masserati, Lisboa, 13 de septiembre 1677. AGS, E, Leg. 2.632.

122 Carta del Abad de Masserati, Lisboa, 17 de mayo de 1677. Consulta del Consejo de Estado, 10 de junio de 1677. AGS, E, Leg. 2.631. Consulta del Consejo de Estado, 29 de septiembre de 1677. AGS, E, Leg. 2.632. 
Pronto el talante entre las dos Cortes tomó un camino más distendido, ya que llegaron noticias de que los portugueses habían suspendido toda movilización militar, publicándose que lo que más convenía a Portugal para su seguridad era la amistad con Castilla. Durante el mes de junio en Madrid se daba por hecho la mediación lusa, aunque lo que más preocupaba era la elección portuguesa de un sujeto como plenipotenciario en Nimega que parecía pro francés, el antiguo embajador portugués en Londres, Francisco de Melo, aunque finalmente el Consejo de Estado accedió a ello ${ }^{123}$. La idea de la francofilia lusa no parece que viniera de la nada, e incluso la diplomacia hispana en otras latitudes se hacía eco de ella. En ocasiones distintos ministros que representaban a Portugal en otras Cortes europeas eran tildados de francófilos por sus homólogos españoles, por lo que en opinión del Consejo de Estado claramente convenía usar todos los medios posibles para «ganarlos» y cambiar su adscripción. Para ello era necesaria la comunicación directa con el embajador español en Lisboa, para que pudiera prevenir cualquier medio o noticia que permitiera un cambio de parecer ${ }^{124}$.

La nueva situación diplomática de quietud permitió que por primera vez se produjera la colaboración militar hispano-portuguesa ante un enemigo común, el avance musulmán por el norte de África. La posibilidad de una colaboración naval en el Mediterráneo había estado presente ya en 1676, pero el Príncipe Pedro no confirmó su oferta a la espera de que la Armada española pudiera estar dispuesta para una acción conjunta, algo que no permitió la Guerra de Mesina ${ }^{125}$. A finales de junio - tras la definitiva aceptación de la mediación - se produjo la petición formal de España para que la flota portuguesa colaborase en el socorro de Orán, ya que la plaza lleva sitiada dos años por las fuerzas musulmanas, que habían aprovechado el contagio de peste por el cual habían perecido 1.300 almas en la ciudad. Orán necesitaba urgentemente grano, pertrechos y soldados, debiendo asegurarse las comunicaciones navales desde la península para que pudieran llegar los suministros necesarios ${ }^{126}$. La necesidad era tal, que también se llegó a pedir la colaboración a Génova y las Provincias Unidas ${ }^{127}$.

Una Armada portuguesa de cinco navíos de porte y una fragatilla de 30 cañones recién construida se pertrechó rápidamente para actuar en el Mediterráneo,

123 Cartas del Abad de Masserati, Lisboa, 7 y 17 de junio de 1677. Orden Real, Madrid, 28 de junio de 1677. Consultas del Consejo de Estado, 23 y 29 de junio, y 22 de julio de 1677. AGS, E, Leg. 2.631. Consultas del Consejo de Estado, 10 de noviembre y 29 de diciembre de 1677. AGS, E, Leg. 2.632.

124 Consulta del Consejo de Estado, 4 de octubre de 1677. AGS, E, Leg. 2.554.

125 Consulta del Consejo de Estado, 24 de mayo de 1676. AGS, E, Leg. 2.630 f. 59.

126 Carta del Consejo de Guerra al Marqués de Monroy, Gobernador de Málaga, 12, 14 y 21 de junio de 1677. Carta del Consejo de Guerra a don Carlos de Herrera Ramírez de Arellano, Asistente de la ciudad de Sevilla, 18 de junio de 1677. AGS, GA, Libro 341 f. 71, 79, 100 y 90. Carta del Consejo de Guerra al Padre Arzobispo de Sevilla, 3 de julio de 1677. Despacho para los grandes y títulos, 16 de julio de 1677. AGS, GA, Libro 341 f. $118 \mathrm{v}$ y $156 \mathrm{v}$.

127 Carta del Consejo de Guerra al Marqués de la Laguna, Capitán General del Mar Océano, 14 de junio de 1677. AGS, GA, Libro 341 f. 84v. 
llevando consigo a más de 1.400 infantes embarcados y 300 piezas de artillería ${ }^{128}$. A la flota se le sumó una galeota de 6 piezas de artillería y 300 soldados veteranos del Alentejo que se incorporaron a los dos Tercios de Armada que iban embarcados, por lo que la flota pudo salir de Lisboa el primero de agosto, dándose formalmente las gracias por parte de España ${ }^{129}$. Las actividades navales de la flota portuguesa fueron bastante limitadas, pero gracias a ella se consiguió el objetivo de suministrar a la plaza los tan ansiados pertrechos que necesitaba ${ }^{130}$. Tras pasar por Málaga, en donde se embarcaron algunas compañías que reforzarían Orán, la flota colaboró con las improvisadas fuerzas navales españolas para introducir víveres en la plaza, y a su vuelta a la península limpió las costas del estrecho de corsarios turcos ${ }^{131}$, intentado sin éxito desembarcar en Arcila y saquear la zona, llegando a Lisboa muy maltratada al tener que soportar dos temporales adver$\operatorname{sos}^{132}$. Meses después, ya en Lisboa, el almirante y el general de la flota portuguesa fueron generosamente compensados con una joya de diamantes y una cadena de oro con la efigie de Carlos II, todo un símbolo de gratitud y de intenciones, que no fue muy bien acogido por el gobierno portugués ${ }^{133}$.

\section{LOS AÑOS FINALES Y LA INSISTENCIA FRANCESA PARA RENOVAR UNA ALIANZA CON PORTUGAL}

La quietud bilateral fue pasajera, y muy pronto Francia sería la culpable de dar el golpe de gracia a las aspiraciones mediadoras de Portugal, enturbiando el acercamiento hispano-portugués. Los franceses insistían en persuadir al príncipe Pedro para que se aliara para obligar a España «a admitir cualquier paz» ${ }^{134}$, reconociéndose el malestar que había provocado en las filas francesas la concesión del socorro de Orán, manteniéndose el ministro francés fuera de la Corte. Sin duda el incendiario memorial presentado en Lisboa en el que Luis XIV se negaba a la mediación lusa, afligió bastante a la corte portuguesa. En él la diplomacia francesa cargaba tintas contra España, recordando a los portugueses que la mediación podía ser costosa, y el fin de conseguir el título de mediador tendría difícil compensación si la paz se rompía. Pero también el escrito recordaba que Pedro no estaba reconocido como rey de Portugal, y que su gobierno no dejaba de tener

128 Cartas del Abad de Masserati, Lisboa, 25 de junio de 1677 (dos de esa fecha). Orden Real, Madrid, 11 de julio de 1677. Consulta del Consejo de Estado, 1 de julio de 1677. AGS, E, Leg. 2.632.

129 Cartas del Abad de Masserati, Lisboa, 20 de julio; 1 y 30 de agosto de 1677. Consultas del Consejo de Estado, 29 de julio y 27 de noviembre de 1677. Carta de su majestad, Madrid, 12 de agosto de 1677. AGS, E, Leg. 2.632.

130 Carta del Consejo de Guerra a don Iñigo de Toledo Osorio, Gobernador y Capitán General de las plazas de Orán, 13 de julio 1677. AGS, GA, Libro 341 f. 142.

131 Cartas del Consejo de Guerra al Marqués de Monroy, Gobernador de Málaga, 27 de julio, 17 de agosto, 4 y 20 de septiembre de 1677. AGS, GA, Libro 341 f. 185; y libro 342 f. 17v, 44 y 61.

132 Consultas del Consejo de Estado, 14 y 18 de octubre 1677. AGS, E, Leg. 2.632.

133 Carta del Abad de Masserati, Lisboa, 20 de diciembre de 1677. Consulta del Consejo de Estado, 9 de enero de 1678. AGS, E, Leg. 2.633.

134 Consulta del Consejo de Estado, 6 de septiembre de 1677. AGS, E, Leg. 2.632. 
una escasa legitimidad. Igualmente se expresaba que no era adecuado que los portugueses mediasen en la paz, ya que así Castilla no les tendría miedo, alegando con una metáfora marinera la futilidad de sus esfuerzos. Para Francia lo que Portugal debía hacer era luchar contra España para forzar una rápida paz, ya que «las ventajas de la guerra son mucho más seguras, juntándose a un rey victorioso por mar y tierra con los socorros de una nación que en ningún tiempo desenbaynó la espada contra Portugal»». De esta manera nada podría contribuir más a la paz general de la cristiandad que la marcha de 15.000 portugueses a 50 leguas de la Corte, hacia la frontera, para invadir Castilla. En el consecuente reparto de victorias los franceses se prometían generosos, pudiendo conseguir así Portugal el reconocimiento y el hueco que le correspondía en Europa ${ }^{135}$.

Si bien España tardó en comprometerse y apoyar la mediación portuguesa, serían los galos los que finalmente contribuirían a su fracaso. Puede que España no estuviera muy implicada con este hecho, pero consiguió que otros Estados reconocieran la mediación, al mismo tiempo que logró que el Emperador tratase al Príncipe de Portugal de la misma manera que al Rey de España, todo lo cual no dejaba de ser un gesto bastante favorable y positivo para el futuro entendimiento ${ }^{136}$. Incluso la negativa de la mediación portuguesa en favor de la británica pudo distanciar momentáneamente a Portugal de Inglaterra. De hecho los primeros advirtieron a España para que no se fiara de los ingleses, alegando que la intervención inglesa en Flandes ${ }^{137}$ estaba más motivada por la negativa de Luis XIV de pagar las sumas acordadas que a una verdadera intención de mediar en el conflicto o contribuir al equilibrio de Europa ${ }^{138}$. Otro factor clave a la mediación sin duda fue que la partida de los representantes lusos se dilató en el tiempo. Si bien el negociador español en Nimega, el Marqués de los Balbases, habían comenzado su viaje el primero de abril de $1677^{139}$, a mediados de julio de 1678 Masserati avisaba que había hablado con los elegidos en Lisboa, por lo que difícilmente la llegada de éstos pudo suponer nada relevante en la paz, consignada por separado el 10 de agosto con los Holandeses y el 19 de septiembre con los españoles ${ }^{140}$.

Tampoco es de extrañar que Francia se negara a la mediación lusa, ya que sin duda desde los inicios del conflicto había actuado de esa manera ante la gran

135 Carta del Abad de Masserati, Lisboa, 16 de agosto de 1677. Copia del Memorial que presentó al Príncipe de Portugal el Ministro de Francia oponiéndose a su mediación. AGS, E, Leg. 2.633.

136 Consultas del Consejo de Estado, 26 de octubre y 8 de diciembre de 1677. AGS, E, Leg. 2.632.

137 A comienzos de 1678 el contingente inglés empezó a llegar a los Países Bajos, llegando a contabilizar hasta 12.000 efectivos, casi la mitad de los esperados. Carta del Marqués de Borgomanero, Londres, 25 de marzo de 1678. Consulta del Consejo de Estado, 14 de diciembre de 1678. AGS, E, Leg. 2.136. Copia de la carta del Conde de Egmont al Secretario Miguel de Iturrieta, 29 de agosto de 1678. AGS, E, Leg. 2.137.

138 Consulta del Consejo de Estado, 1 de noviembre de 1678. AGS, E, Leg. 2.634 f. 104.

139 Cuenta y cargo del dinero que Pablo Spínola Doria, Marqués de los Balbases ha recibido y se le ha remitido para el viaje al congreso de Nimega, desde 1 de abril de 1677. AGS, E, Leg. 3.920.

140 Carta del Abad de Masserati, Lisboa, 18 de julio de 1678. AGS, E, Leg. 2.634 f. 25. 
mayoría de las iniciativas presentadas, las iniciales de España ${ }^{141}$ y el Elector de Maguncia ${ }^{142}$ a comienzos de la contienda. Más receptiva fue ante la propuesta inglesa de finales de 1675, la cual fue retrasada continuamente ante los éxitos militares franceses y la aversión holandesa ${ }^{143}$, aunque finalmente ésta mediación sería la que daría lugar a la paz, no sin que antes el bloque aliado consiguiera que se repatriaran las tropas inglesas que servían a los franceses ${ }^{144}$.

Independientemente de todos los factores, Portugal pagó cara su neutralidad ante Francia, generándose cierta incertidumbre en el país vecino, que parecía más consciente de su debilidad externa y su necesidad de encontrar un potente aliado que pudiese garantizar su seguridad y la de sus colonias. Todo ello empezó a preocupar a España, ya que a pesar del relativo estado de paz, en el verano de 1678 los portugueses enviaron a un ingeniero a recorrer la frontera, mientras que en Lisboa se pasaba alarde a varias unidades militares y se formaba un Tercio de 700 hombres a cargo de los comerciantes ${ }^{145}$. Las sospechas de que Portugal podría quedar aislado al negar a Francia su tan ansiada alianza quizá no fueran tan descabelladas. En los contactos de paz y las negociaciones mantenidas entre Francia y España de manera esporádica, más que como sondeo que otra cosa, algunas versiones no muy verosímiles hablan de que incluso una de las cláusulas de un hipotético acuerdo era que Francia se abstendría de ayudar a Portugal en caso de un intento de reconquista ${ }^{146}$.

Por tanto, era lógico que Portugal cuidase sus fronteras, incrementado su guarnición para presionar a España, pero lo más preocupante era la colaboración naval mantenida entre franceses y portugueses al amparo de viejo tratado de 1667, la cual incluso llegó a oídos del propio Emperador, que a través de los españoles intentaba encontrar sentido a las inquietantes noticias que le habían llegado y que indicaban que Portugal no era tan neutral ${ }^{147}$. La colaboración naval entre Francia y Portugal había sido habitual ya en el pasado. En 1646 cinco navíos portugueses colaboraron en el asedio de Porto Longone, en los Presidios Toscanos, formando parte de la escuadra del Duque de Brezé, y posteriormente otros cuatro navíos se incorporaron con la armada del Arzobispo de Burdeos en el Atlántico ${ }^{148}$. A lo largo de la década de 1670 la posibilidad francesa de establecer una base naval segura en la costa portuguesa se mostró una prioridad, ya que de ese modo podrían conseguir el paso del Atlántico al Mediterráneo de manera se-

141 Consultas del Consejo de Estado, 12 de febrero y 24 de abril de 1672. AGS, E, K Leg. 1.400. Minuta al Conde de Molina sobre la forma de gobernarse en la mediación con Holanda, 12 de octubre de 1672. AGS, E, K Leg. 1.413.

142 Consulta del Consejo de Estado, 26 de febrero 1673. AGS, E, K Leg. 1.402.

143 Consultas del Consejo de Estado, 4 de abril y 12 de diciembre de 1675. AGS, E, Leg. 2.551.

144 Consultas del Consejo de Estado, 27 de julio y 30 de noviembre de 1677. AGS, E, Leg. 2.554.

145 Consultas del Consejo de Estado, 20 y 30 de julio 1678. Cartas del Abad de Masserati, Lisboa, 18 de julio y 21 de noviembre de 1678. AGS, E, Leg. 2.634 f. 10, 14, 25 y 133.

146 SERRANO DE HARO, (Madrid, 1992): 574/575.

147 Carta del Abad de Masserati, Lisboa, 1 de agosto de 1678. AGS, E, Leg. 2.634 f. 17.

148 Cartas del Abad de Masserati, Lisboa, 26 de septiembre de 1678. AGS, E, Leg. 2.634 f. 80. 
gura. Esto ayudaría a las aguadas y a pertrechar las Armadas francesas que se dirigían a atacar las posiciones holandesas en África o las Indias, al mismo tiempo que se atemorizaba a los españoles ante la posibilidad de que la flota de la plata fuera interceptada.

A finales de febrero de 1678 el embajador Masserati avisaba que una Armada francesa de 7 navíos grandes, 4 de fuego y 10 cargados con infantería - con un total de 8.000 hombres entre marineros e infantería embarcada- habían sido pertrechados en los almacenes que los franceses disponían en Lisboa y Faro, e incluso se esperaban más buques. Ante ello el Consejo de Estado dio orden para que se incrementara la guarnición de las plazas costeras más amenazadas, intentando averiguar todo lo posible sobre el destino de dicha Armada. Miedos a los que se unía el hecho de que en Brest quedaba aparejada una escuadra de 6 navíos de guerra preparados para actuar en Mesina, que se esperaba que pasaran por Faro antes de alcanzar el Mediterráneo ${ }^{149}$.

Los temores españoles eran ecos de guerra franceses que llegaban tarde y no se correspondían con la realidad. La fuerte escuadra francesa avistada en Portugal realmente se había divisado meses atrás, y era la escuadra del Almirante Jean II d'Estrées ${ }^{150}$ que volvía a América a combatir a los holandeses tras su derrota en Tobago, intentado así recuperar las posiciones perdidas frente a los neerlandeses ${ }^{151}$. Poco después se demostró que la escuadra de 6 navíos franceses que se esperaba en Faro nunca se había despachado, ante la precipitada retirada francesa de Mesina ${ }^{152}$. De esta manera el Almirante holandés Evertsen debió luchar con esa escuadra cuando la que comandaba volvía a Holanda tras apoyar a los españoles en el Mediterráneo, corroborando que no había navíos de guerra franceses en Faro para alivio de la flota de Galeones ${ }^{153}$. Lo que sí que se encontró en Faro fue que numerosos navíos mercantes franceses habían dejado mercaderías, y que se pensaban introducir 1.600 fardos de ropa ilegalmente para enviarlos a América ${ }^{154}$. Cuestión que se complicaba con el cada vez más abundante comercio ilegal, especialmente centrado en la saca de plata labrada mediante veredas poco transitadas de Castilla, Extremadura y Andalucía. El negocio había aumentado notablemente, llegando su rentabilidad al $8 \%{ }^{155}$. A esto se su-

149 Cartas del Abad de Masserati, Lisboa, 27 de febrero y 28 de marzo de 1678. Instrucciones de lo que ha de ejecutar el cónsul Pablo Estebes en la comisión que se le encarga de ir a asistir en el puerto y ciudad de Faro en el Algarbe, Lisboa, 3 de marzo de 1678. Consultas del Consejo de Estado, 8 y 22 de marzo de 1678. AGS, E, Leg. 2.633.

150 DESSERT, 1996, 187/191 y 249/252. RICHER, 1786.

151 MARLEY, 2008 1, 284/291. BLACK, 1999, 43/44.

152 RIBOT, 2002, 121/122.

153 Consulta del Consejo de Estado, 7 de abril de 1678. AGS, E, Leg. 2.703.

154 Consulta del Consejo de Estado, 31 de marzo de 1678. AGS, E, Leg. 2.633.

155 Carta del Abad de Masserati, Lisboa, 10 de enero de 1678. Consulta del Consejo de Estado, 25 de enero de 1678. AGS, E, Leg. 2.633. 
maba la gran cantidad de moneda falsa que se labraba en Portugal y se introducía en España ${ }^{156}$.

A pesar de que estaba cerca la firma del Tratado de Nimega, durante 1678 Francia continuó apelando a los portugueses a la renovación de su alianza, aunque con mucho menos ahínco que en tiempos precedentes. Es probable que con ello tratara de distraer a los españoles para que mantuvieran los contingentes que mantenían en la frontera portuguesa y no pudiera socorrer con más tropas Flandes y especialmente Cataluña. De hecho, en mayo capitulaba la plaza de Puigcerdá ${ }^{157}$, máximo exponente de la progresión francesa en Cataluña. Por otro lado parece que las iniciativas francesas tratasen más de castigar a los portugueses por su obstinada resistencia a aliarse con el Rey Sol que a atraer su colaboración. El representante francés, si bien continuaba pidiendo que Portugal declarase la guerra a España, retomaba la vieja idea de que los lusos debían reembolsar las cantidades suministradas por Francia durante la Guerra de Restauración, que podía ascender a cerca de tres millones de cruzados, aproximadamente dos millones de reales de a ocho. Pese a ello, según Masserati los portugueses mantendrían su neutralidad, y más ante los ecos de paz que se avecinaban ${ }^{158}$.

El fin de la contienda significaría para Francia la culminación de sus éxitos militares y políticos, y más especialmente éstos últimos, ya que además de sus ganancias territoriales conseguía debilitar la coalición forjada para luchar contra su expansión al establecer una paz separada con todos sus enemigos. Francia había utilizado hábilmente a Portugal en sus intentos sin conseguir nunca comprometer a los lusos, que se zafaron de su presión no viéndose obligados a una nueva guerra. Es difícil saber si Pedro el pacífico, tenía tan claro su no alineamiento ante Francia. Su neutralidad propició que Portugal se recuperara de la pasada guerra —algo que no pudo conseguir la Monarquía Hispánica-, al mismo tiempo que permitía el reforzamiento de sus posiciones coloniales, las guarniciones fronterizas y su armada, bazas políticas que con mucho éxito fueron utilizadas ante los españoles. Incluso el miedo del pueblo a una invasión española sirvió como aglutinante y como contrapeso a las tensiones internas. Realmente Portugal no debía temer nada de España, que por aquel entonces no tenía intención de formular acción militar alguna para reconquistar el país vecino, ya que realmente sus fuerzas fronterizas nunca estuvieron capacitadas para ello. Si bien en los entresijos de la corte española hubo siempre el anhelo de una re-unión ibérica ${ }^{159}$, nunca se planteó que esta podría realizarse por las armas, sino por medio de matrimo-

156 Carta del duque de Veraguas, La Coruña, 15 de octubre 1678. Consulta del Consejo de Estado, 1 de noviembre de 1678. AGS, E, Leg. 2.634 f. 103 y 102.

157 STORRS, 2006, 3.

158 Cartas del Abad de Masserati, Lisboa, 5 y 26 de septiembre, y 13 de noviembre de 1678. AGS, E, Leg. 2.634 f. 68,80 y 113.

159 MARTÍN MARCOS, (Lisboa, 2011): 67-84 
nios ${ }^{160} \mathrm{o}$ ante la falta de un sucesor ${ }^{161}$, cuestión que también pretenderían los portugueses ${ }^{162}$.

A pesar de los argumentos franceses, la colaboración militar entre España y Portugal se produjo, ya que ambas monarquías tenían intereses comunes frente a la expansión norteafricana, pero para nada eso significó que las reticencias, recelos o miedos cesasen haciendo que el entendimiento fuera muy limitado. La Paz de Nimega no consiguió que las tensiones fronterizas acabasen al rebajarse la presión francesa, sino más bien todo lo contrario, entrando en la palestra un nuevo factor, las fronteras americanas. De hecho, pocos años después, en 1681, la escalada de tensión provocada por la destrucción de la colonia de Sacramento generaría importantes miedos de guerra, y la posibilidad de un conflicto bélico entre Madrid y Lisboa estuvo más cerca que nunca.

\section{BIBLIOGRAFÍA}

ABREU Y BERTODANO, José Antonio, Colección de los Tratados de Paz, alianza, garantía..., Reinado de Carlos II. Parte I, Madrid, Diego Peralta et alii, 1751.

ALMIRANTE, José, Bosquejo de la Historia Militar de España, Tomo III, Madrid, Sucesores de Rivadeneyra, 1923.

BENEVIDES, Francisco da Fonseca, Rainhas de Portugal, 2 vols., Lisboa, Livros Horizonte, 1879.

BÉRENGER, Jean, Turenne, París, Fayard, 1987.

BLACK, Jeremy, From Louis XIV to Napoleon: The Fate of a Great Power, Londres, Routledge, 1999.

CARDIM, Pedro, "NNem tudo se pode escrever". Correspondencia diplomática e información "política" en el Portugal del seiscientos", Cuadernos de Historia Moderna. Anejos 4 (Madrid, 2005): 95/128.

DE BERNARDO ARES, José Manuel «El iberismo como alternativa político-dinástica al francesismo y al austracismo (1668-1725)", Anais de História de Além-Mar, 8 (Lisboa, 2007):11/36.

DE CAIX DE SAINT-AYMOUR, Amédée, Recueil dês instructions aux ambassadeurs et ministres de France depuis les traités de Westphalie jusqu'a la Révolution Française, Portugal, Tomo III, París, Felix Alcan, 1886.

DESSERT, Daniel, La Royale. Vaisseaux et marins du Roi-Soleil, París, Fayard, 1996.

DRUMOND BRAGA, Isabel y DRUMOND BRAGA, Paulo, Duas Rainhas em Tempo de Novos Equilíbrios Europeus: Maria Francisca Isabel de Saboia. Maria Sofia Isabel de Neuburg, Lisboa, Círculo de Leitores, 2011.

DU MONT, Pierre, Le ceremonial diplomatique des cours de l'Europe, oucollection des actes, memoires et relations..., Tomo II, Ámsterdam, Den Haag, 1739, p. 382.

ESTRADES, conde de, Lettres, memoires et négotiations de Monsieur le Comte d'Estrades..., Tomo VII, Londres, J. Nourse, 1743.

GIL PUYOL, Xavier, "Visión europea de la Monarquía española como Monarquía compuesta, siglos XVI y XVII", en C. Russell y J. A. Gallego, Las monarquías del Antiguo Régimen ¿Monarquías compuestas?, Madrid, Complutense,1996. 65/95.

160 Carta del Marqués del Carpio, Lisboa, 16 de febrero de 1668. AGS, E, Leg. 2.614.

161 Consulta del Consejo de Estado, 25 de enero de 1675. AGS, E, Leg. 2.629 f. 8.

162 DE BERNARDO ARES, (Lisboa, 2007):11/36. 
GODINHO, Vitorino M. «Portugal y su Imperio», en Francis Ludwig Carsten (Ed.), Historia del Mundo Moderno, Vol. V, La Supremacía de Francia 1648-1688, Barcelona, Ramón Sopena, 1990, 286/296. Versión española de: The New Cambridge Modern History, Cambridge, Cambridge University Press, 1971.

HERRERO SÁNCHEZ, Manuel, El acercamiento hispano-neerlandés (1648-1678), Madrid, CSIC, 2000.

LEAL DE FARIA, Ana Maria Homem, Os Cadernos de Duarte Ribeiro de Macedo. Correspondência Diplomática de Paris, 1668-1676, Lisboa, MNE-IDI, 2007.

LORENZO PINAR, Francisco Javier y VASALLO TORANZO, Luis, Diario de Antonio Moreno de la Torre (1673-1679), Zamora, Instituto de Estudios Zamoranos Florián de Ocampo, 2001.

LYNN, John A., The Wars of Louis XIV 1667-1714, Londres, Longman, 1999.

MARLEY, David, Wars of the Americas: A Chronology of Armed Conflict in the Western Hemisphere, Vol. 1, Santa Barbara-California, ABC-CLIO, 2008.

MARTÍN MARCOS, David, «Visiones españolas de algunos anhelos prohibidos en el Portugal de los Braganza (1668-1700): en torno a una nueva unión ibérica», Ler História, 61 (Lisboa, 2011): 67-84.

NIETO NUÑO, Miguel (ed.), Diario del conde de Pötting, embajador del Sacro Imperio en Madrid (1664-1674), Tomo II, Madrid, Ministerio de Asuntos Exteriores, 1990.

PENIM DE FREITAS, Jorge, O Combatente durante a Guerra da Restauração. Vivência e comportamentos dos militares ao serviço da Coroa portuguesa, Lisboa, Prefácio, 2007.

QUINCY, Marqués de, Histoire militaire de Louis le Grand roi de France, Vol I, París, Denis Mariette, 1736.

RIBOT, Luis, La Monarquía de España y la Guerra de Mesina (1674-1678), Madrid, Actas, 2002.

RICHER, Adrien, Vies de Jean d'Estrées, Duc et Pair, Maréchal de France, Vice-Amiral, et Vice-Roi de l'Amérique; et de Victor-Marie d'Estrées, son fils, Duc et Pair, Maréchal de France, ViceAmiral, et Vice-Roi de l'Amérique, París, Belin, 1786.

RODRÍGUEZ HERNÁNDEZ, Antonio José, La ciudad y la guarnición de Ceuta (1640-1700). Ejército, fidelidad e integración de una ciudad portuguesa en la Monarquía Hispánica, Ceuta, Instituto de Estudios Ceutíes, 2011.

SERRANO DE HARO, Antonio, «España y la Paz de Nimega», Hispania, 181 (Madrid, 1992): 574-575.

STORRS, Christopher, The Resilience of the Spanish Monarchy 1665-1700, Oxford, Oxford University Press, 2006.

VALLADARES, Rafael, La rebelión de Portugal. Guerra, conflicto y poderes en la Monarquía Hispánica (1640-1680), Valladolid, Junta de Castilla y León, 1998. 
